\title{
A SELEÇÃO DE CANDIDATURAS NO DEM, PMDB, PSDB E PT NAS ELEIÇÕES LEGISLATIVAS FEDERAIS BRASILEIRAS DE 2010: PERCEPÇÕES DOS CANDIDATOS SOBRE AFORMAÇÃO DAS LISTAS ${ }^{1}$
}

\author{
Bruno Bolognesi
}

\begin{abstract}
RESUMO
Este trabalho tem por objetivo realizar uma análise do processo de escolha de candidaturas nos quatro maiores partidos brasileiros (DEM, PMDB, PSDB e PT), levando em conta a percepção dos candidatos sobre tal processo uma perspectiva ainda pouco abordada no Brasil. A partir desta análise, estabeleceram-se critérios empíricos para a mensuração da democracia interna nos partidos políticos. Para tanto, aplicamos um survey a 120 candidatos à deputado federal nas eleições de 2010. O marco de análise utilizado foi o proposto por Freidenberg (2003) para a definição e mensuração de democracia interna e Hazan e Rahat (2010) para o processo de seleção de candidatos. A hipótese é que seleções mais inclusivas e realizadas por meio de votação produzem partidos mais democráticos. Os resultados apontam que partidos com participação de instâncias organizativas médias (como delegados) e que mobilizam o voto para a tomada de decisão nem sempre apresentam melhores índices de representatividade.
\end{abstract}

PALAVRAS-CHAVE: seleção de candidatos; democracia interna; partidos políticos; recrutamento político, eleições.

\section{INTRODUÇÃO}

Para Prewitt (1970) o recrutamento pode ser entendido como a metáfora da "caixa chinesa": no tradicional artefato oriental, as caixas menores são colocadas dentro das maiores, até que o ajuste da última deixe o mínimo de espaço possível. Da mesma forma, a partir de uma população dispersa, um processo lento e contínuo estreitaria os caminhos de acesso ao poder. De um grande número de elegíveis, surgem os interessados e, em seguida, os politicamente ativos, dos quais somente alguns poucos serão eleitos. Czudnowski (1975) argumenta na mesma linha, ao entender que o recrutamento político envolve diferentes etapas que podem ter seu início nos estágios primários de socialização até culminar com a ocupação de um posto político formal. Contudo, diferentemente das análises de recrutamento legislativo ${ }^{2}$ que entendem a formação de elites políticas como um todo, o estudo

\footnotetext{
1 Este artigo é fruto dos terceiro e quarto capítulos da tese de doutorado que apresentamos no programa de pós-graduação em Ciência Política da Universidade Federal de São Carlos.

2 É importante frisar que a diferença é que os estudos de recrutamento estão mais ligados a traços comparativos entre elites e populações mais gerais, enquanto que os estudos de seleção de candidatos se voltam para análises institucionalistas.
}

de seleção de candidatos tem privilegiado duas instâncias, sendo a primeira o tempo do processo e a segunda é o local onde ocorre.

Como colocam Rahat e Hazan (2001), a seleção de candidatos se refere ao momento particular no qual os indivíduos abandonam sua condição de qualificados politicamente e passam a integrar um grupo específico de candidatos responsáveis por representar eleitoralmente suas filiações. Ou seja: a dimensão tempo (no sentido de trajetória de vida) é crucial na medida em que oferece o ponto exato em que aspirantes passam a integrar um corpo política e legalmente habilitado para disputar eleições. A segunda dimensão, a do local, se refere à noção de partidos políticos como instituições singulares e detentoras legítimas do controle sobre a representação política (BRAGA, 2008).

O ponto de partida aqui é que a seleção de candidatos é um processo privilegiado para entender o modo como os partidos políticos elaboram a disputa pelo poder. Essa disputa tem importantes conseqüências para os regimes democráticos e para os partidos políticos tomados como organizações que atuam tanto na arena legislativa, quanto na eleitoral (RAHAT, 2009). A seleção de candidatos é o modo pelo qual podemos ver quem é recrutado (GALLAGHER \& MARSH, 1988) e que permite observar como ocorre a dinâmica intra- 
partidária e os conflitos internos (WARE, 1996). Além disso, serve como um elemento fundamental para avaliarmos a democracia em si, já que neste regime espera-se que suas instituições sejam também dotadas internamente de práticas democráticas (BILLIE, 2001; FREIDENBERG, 2003).

A seleção de candidatos é apontada como uma função central dos partidos políticos, senão como a principal função desempenhada por eles. Schattsschneider (1942) chega a afirmar que quem controla o processo de seleção de candidatos se torna "o dono do partido". Porém, a maior parte dos trabalhos que descrevem a seleção de candidatos como fundamental refere-se usualmente às conseqüências externas que dele podem resultar a fim de justificar sua relevância. Billie (2001) mostra que a participação no processo de seleção de candidatos pode servir como um indicador para compreender o quão representativas são as instituições políticas de um dado país. Cross (2008) sugere que a seleção de candidatos é o principal "filtro" em operação nos partidos e determina na maior parte a oferta de futuros representantes. Outros estudos, essencialmente Rahat, Hazan e Katz (2008) e Hazan e Rahat (2010), apontam que a seleção de candidatos tem também importantes conseqüências para a vida interna dos partidos políticos, incrementando ou diminuindo níveis de accountability, participação e competição. Por fim, Hazan e Rahat (2007) e Koop e Bittner (2011) mostram que a seleção de candidatos tem impacto não somente para os partidos tomados como unidades de análise, mas também no comportamento dos eleitos e conformação das bancadas parlamentares.

Em linhas gerais, a seleção de candidatos afeta diversas esferas da vida política nas democracias representativas. Porém, operacionalmente, a seleção de candidatos tem sido mobilizada como indicador empiricamente viável para avaliarmos diferentes graus de democracia interna nos partidos políticos. Isso ocorre, em grande parte, pela escassez de estudos sobre seleção de candidatos fora da Europa e Estados Unidos, que é ainda maior no campo das investigações que conseguem relacionar empiricamente este processo com comportamentos políticos.

É justamente sob este último aspecto operacional que centraremos nossa análise. Saber em que medida os partidos são mais ou menos democráticos ao escolherem seus candidatos pode ser um bom indicativo de como se dão as relações de poder no interior do partido. Por um lado, Freidenberg (2003) afirma que os níveis de democracia interna dos partidos políticos podem ser efeitos do processo de institucionalização partidária. A adoção de práticas regulares e da participação de membros do partido de forma transparente serviria como referencial para a conduta dos atores partidários. Institucionalização, entendida como rotinização de procedimentos, poderia de fato aumentar os graus de previsibilidade dos atores. Por outro lado, não é possível estabelecer nenhuma associação a priori entre institucionalização partidária e seleção de candidatos. É preciso verificar empiricamente se a relação institucionalização - seleção de candidatos - democracia interna encontra apoio nas evidências empíricas. Um partido que adote o clientelismo como procedimento universal a ponto de institucionalizá-lo pode não contar com bons indicadores de democracia em seu interior (DESPOSATO, 2006; LEVITSKY, 2009).

Ao mesmo tempo, a democracia interna dos partidos políticos pode ser entendida como uma conseqüência da seleção de candidatos. Por exemplo: quando o processo recruta parcelas mais diversas da sociedade ou conta com a entrada de minorias, aumentando níveis de representatividade. A inserção de setores diversos da sociedade poderia ser encarada como aumento dos níveis de democracia quanto ao seu conteúdo. Por outro lado, podemos encarar a seleção de candidatos como mais ou menos democrática quanto aos procedimentos mobilizados para a tomada de decisão: seleções realizadas por sistemas de votação ou indicação poderiam caracterizar opostos entre mais ou menos democráticos. O envolvimento dos membros e eleitores no processo poderia ser outro elemento procedimental para entender os níveis de inclusividade e democracia.

Entretanto, a seleção de candidatos é apenas um indicador possível para mensurarmos democracia interna. Podemos imaginar que um partido tenha um avançado sistema de votação para determinar a composição de suas listas eleitorais, mas é o líder quem toma as decisões mais importantes do partido, tais como distribuição de recursos de campanha (FREIDENBERG, 2006). O que sustentamos é que a seleção de candidatos pode ser um sinal que, comparativamente, indica quais os partidos mais democráticos. Ou seja, este é um indicador relativo e não absoluto sobre democracia interna.

Este artigo apresenta dados referentes aos processos de seleção de candidatos conduzidos pelo PT, DEM, PSDB e $\mathrm{PMDB}^{3}$ durante as eleições para Deputado Federal em $2010^{4}$. A partir de um survey

\footnotetext{
3 A escolha destes partidos se deve basicamente a três fatores: i) são celebrados na literatura como os quatro maiores partidos do Brasil (VEIGA, 2007); ii) são os partidos que mais lançam candidatos desde as eleições de 1996 (BRAGA; VEIGA; MIRIADE, 2009); iii) são os quatro partidos que conseguiram
} 
aplicado aos candidatos dos quatro partidos, mapeamos as percepções destes quando foram escolhidos para comporem as listas eleitorais naquele ano. É importante salientar que, como lembram Hazan e Rahat (2010), a pesquisa sobre seleção de candidatos deve centrar-se num ponto específico do tempo e deve ter o partido político como unidade de análise $e^{5}$. Fazemos uma comparação entre as diferenças e similitudes entre os quatro partidos que mais lançam candidatos a deputado federal no Brasil ${ }^{6}$, sabendo que esses partidos partilham de um aparato institucional-legal equivalente, e que operam num mesmo sistema eleitoral e partidário com a disputa de um eleitorado comum. Outros estudos evidenciam que a comparação ao longo do tempo pode ser útil para compreender processos de (des) democratização e outros movimentos internos do partido (HAZAN \& RAHAT, 2010). Assim, o objetivo central é realizar uma comparação entre os partidos, a partir do processo de seleção de candidatos, a fim de estabelecer um gradiente de democracia interna nos partidos no ano em questão.

A hipótese que sustenta esse trabalho, a partir de Freidenberg (2003), é que a natureza da seleção de candidatos, sua direção e foco, afetam também os níveis de democracia dos partidos. A seleção de candidatos é, portanto, a variável independente ${ }^{7}$. Assim, analisaremos a democracia interna dos processos de seleção tendo em vista dois componentes: i) os processos de seleção de candidatos em si, em termos de quão centralizados e inclusivos eles são; ii) as

nas últimas eleições conquistar, cada um, mais de $10 \%$ dos votos do eleitorado (BRAGA \& BOURDOUKAN, 2007).

4 A fonte dos dados é a pesquisa Como se faz um deputado: a seleção de candidatos para Deputado Federal nas Eleições de 2010, da qual participaram as seguintes universidades: UFSCar, UFPR, UFS, PUC-RS, UFPA. Foram 120 candidatos à deputado federal do Paraná, São Paulo, Sergipe, Pará e Rio Grande do Sul que responderam este survey respeitando a proporção de candidatos total de cada estado. A amostra é representativa para os quatro partidos analisados, contando com um ' $n$ ' mínimo de 30 questionários para cada um, porém não é representativa para o Brasil tomado como um todo. $\mathrm{O}$ ' $\mathrm{n}$ ' da amostra deve ser encarado como um estudo de caso, o que não nos permite extrapolações estatísticas para toda a população de candidatos nas eleições legislativas para a Câmara Federal em 2010.

5 É importante realizar a distinção de que mesmo que a unidade de observação sejam os candidatos dos partidos tomados individualmente, eles refletem o comportamento do partido político como um todo, tomado então como unidade de análise.

\section{Cf. BRAGA \& BOLOGNESI (2013).}

7 Mesmo tratada deste modo, propomos algumas explicações para as diferenças entre os métodos de seleção de candidatos utilizados pelos partidos ao longo do texto. conseqüências do processo de seleção, o nível de representatividade dos outputs resultantes, bem como questionar em que medida esse é um critério válido para mensurar democracia no interior dos partidos.

$\mathrm{O}$ artigo está dividido em três grandes partes, que se apresentam após esta introdução, da seguinte forma: a segunda seção do texto traz o debate de como a seleção de candidatos pode servir como um indicador empiricamente viável para mensurarmos níveis de democracia no interior dos partidos políticos. Em seguida, nas seções 3, 4 e 5, apresentamos os dados obtidos com o survey, mantendo o foco na questão interna da seleção de candidatos a partir de quatro dimensões que compõem seleções mais ou menos democráticas: requisitos de inclusividade para a candidatura; inclusividade do selectorate; centralização e forma de escolha - por votação ou indicação.

Por fim, as conclusões apontam as conseqüências das seleções de candidatos, as limitações do uso dessa variável como critério único e sugere uma agenda de pesquisa que a leve em conta como um campo promissor para análise organizacional dos partidos políticos.

\section{II.SELEÇÃO DE CANDIDATOS E DEMOCRACIA INTERNA NOS PARTIDOS POLÍTICOS.}

É consenso na literatura que uma das principais funções dos partidos políticos é escolher candidatos que irão disputar as eleições e representar o partido nos parlamentos ${ }^{8}$. A importância de se estudar como os candidatos chegam até a lista final de nomes se deve ao fato de que a seleção de candidatos determina em larga escala a distribuição de poder no interior do partido (FREIDENBERG, 2003). Quem controla a seleção de candidatos, controla o "coração" do partido (RANNEY, 1965) e este processo é o principal canal pelo qual a sociedade acessa e se converte em elite política (KATZ, 2001). Sobre isso, Gallagher e Marsh (1988) mostram que os processos de nominação de candidatos eliminam $99,96 \%$ dos possíveis elegíveis, restando para o crivo do voto apenas $0,04 \%$. Ou seja, é na seleção de candidatos que se determina em larga medida qual será o perfil dos eleitos e quais serão as políticas públicas que o partido defenderá ao longo dos mandatos. Desse último ponto de vista, seleções de candidatos mais democráticas deveriam produzir legislaturas mais representativas, incrementando não

\footnotetext{
8 Uma série de autores enfatiza que a seleção se tornou cada vez mais importante na medida em que os partidos políticos se diferem de outras instituições pelo seu objetivo intrínseco de disputar espaços de poder (BILLIE, 2001; FREIDENBERG, 2003; SCHATTSCHNEIDER, 1942; PANEBIANCO, 2005; entre outros).
} 
só a forma com que se conduz o regime, mas também o conteúdo das democracias 9 .

Contudo, o que é, afinal, democracia interna? O uso cotidiano deste termo pode levar a confusões conceituais e análises enfraquecidas ao nos depararmos com altos níveis de suposta inclusividade e participação. O movimento dos partidos políticos em clamar por suas bases em momentos de crise organizativa ou envolvimentos em escândalos de corrupção, como apontam Pennings e Hazan (2001), pode refletir-se num maior controle das elites partidárias sobre as zonas de incerteza dos partidos do em maior democratização de fato. Para cumprir um escrutínio mais completo de critérios que não se restrinjam à inclusão de novos atores, Freidenberg (2009) define que democracia interna está associada a três indicadores: i) a seleção de candidatos aos cargos eletivos e partidários; ii) participação de minorias e setores sub representados no processo de definição programática do partido e; iii) prestação de contas dos eleitos do partido aos filiados. A seleção de candidatos, segundo a autora, merece destaque, já que é o processo chave para determinarmos níveis de democracia interna. Já os outros dois são parte e conseqüência, respectivamente, do primeiro.

Como anunciam Hazan e Rahat (2010), não é apenas incluindo novos atores no processo de seleção de candidatos que níveis de democracia são aumentados. Além da ampliação da participação (ou seja, da inclusividade), a forma como os novos membros atuam, por votação ou indicação, reflete também indicadores fundamentais para que a democracia interna ganhe corpo no interior das agremiações políticas. Porém, a combinação entre estas duas dimensões pode levar a enganos ao classificarmos os partidos: Rahat (2009) e Katz (2001) sugerem que a inclusão de um grande número de filiados ou a abertura da seleção de candidatos na forma de primárias tende a aumentar o espaço de manobra das elites partidárias, diluindo o

\footnotetext{
${ }^{9}$ As transformações ocorridas recentemente nos partidos europeus mostraram uma tendência em democratizar procedimentos internos de tomada de decisão e de escolha de líderes como uma possível resposta a crises eleitorais e de legitimidade dos partidos políticos frente ao eleitorado cada vez mais midiatizado e menos envolvido com o cotidiano partidário (PENNINGS \& HAZAN, 2001). Esse movimento produziu conseqüências também na América Latina, onde muitos partidos reformaram suas formas de eleições internas e ampliaram a participação dos filiados nas decisões importantes dos partidos (FREIDENBERG, 2003). Tal quadro de mudanças abriu fronteira para a avaliação dos níveis de democracia interna nos partidos, tomando por conta a proposição de Mainwaring e Scully (1997) que, para sistemas partidários estáveis e democráticos, é preciso que existam dentro destes partidos de mesma natureza.
}

poder de instâncias intermediárias do partido numa massa de votantes que acaba por somente homologar decisões consertadas por elites políticas ${ }^{10}$. Ou seja, apenas o incremento da participação política pode não ser exatamente um aumento da democracia nos $\operatorname{partidos}^{11}$.

Por outro lado, do ponto de vista do arranjo organizativo, um aumento na participação e na inclusividade de quem seleciona os candidatos seria suficiente para mensurarmos democracia interna nos partidos. O debate com os defensores da democracia como conteúdo - supondo que o aumento da representatividade ou da pluralidade social nos partidos é um indicador válido - conclui que a mensuração de democracia interna é dependente destes conteúdos, quando na verdade o inverso é o que ocorre. Não é possível tomar uma conseqüência de um procedimento, (por exemplo, a seleção de candidatos) como indicador para classificá-lo.

A democracia interna só pode ser entendida do ponto de vista procedimental do conceito: dizer que mais mulheres compõem a lista final de candidatos e por isso a seleção foi mais democrática é tomar a conseqüência pela causa, já que todos os processos políticos contam com certa dose de incerteza (FREIDENBERG, 2009). Isso não quer dizer que não devamos direcionar nossos esforços para as conseqüências do processo de seleção de candidatos. Somente ao entender a relação entre seleção e os seus efeitos é que podemos diagnosticar quais os problemas que podem ser compreendidos, resolvidos ou melhorados (FREIDENBERG, 2002).

$\mathrm{Na}$ tentativa de criar um equilíbrio entre inclusividade e democracia, Hazan e Voerman (2006) mostram que processos que descentralizam radicalmente e aumentam severamente a participação da escolha de candidatos tendem a produzir fenômenos clientelísticos, candidatos personalistas e pouco leais aos seus partidos. De modo diverso ao da proposta inicial de Flávia Freidenberg, optamos por classificar como mais democráticas aquelas seleções nas quais

\footnotetext{
10 Além disso, Barnea e Rahat (2007) mostram que fatores externos como a inserção de um novo partido no sistema eleitoral, mudanças na estrutura de relações sociais ou nas dinâmicas internas dos partidos políticos, podem determinar a escolha por democratizar o processo de seleção de candidatos.

11 Freidenberg (2009, p. 290) mostra evidências de que a abertura de processos de seleção para primárias em uma série de partidos latino-americanos não levou a uma melhora imediata na qualidade dos representantes eleitos, dando fôlego empírico à tese de que o incremento na participação e na inclusão deve ser também qualificado.
} 
predominam instâncias intermediárias do partido, como delegados ou colégios de membros com poder de barganha política. Essa opção segue a mesma linha apresentada por Hopkin (2001) que afirma que processos de seleção muito inclusivos (como as primárias) tendem a diminuir o poder barganha dos participantes em relação aos líderes. O aumento desqualificado de quem seleciona os candidatos cria um ambiente no qual, por um lado, aumentam-se as possibilidades de o eleito não saber a quem se dirigir para prestar contas, ou que, por outro, o selecionado venha a corresponder à média da preferência dos selecionadores, o que limita as probabilidades de aumento da representação de minorias - sem falar no aumento de custos monetários e políticos que seleções realizadas por primárias acarretam.

Conseqüentemente, o procedimento metodológico adotado aqui visa que, através da seleção de candidatos, possamos estabelecer indicadores mensuráveis para níveis de democracia interna nos quatro grandes partidos brasileiros, tendo em vista os critérios acima apresentados quanto aos procedimentos na tomada de decisão. A hipótese de trabalho que testamos é dada por Freidenberg (2006): será mais democrático o partido que apresenta processo de seleção de candidatos mais inclusivo, com a participação de um maior número de atores (desde que empoderados pela organização partidária) e quando o processo for mais descentralizado. Por outro lado, processos de seleção levados a cabo por um número muito restrito de atores (como um único líder) e mais centralizados são menos democráticos.

Quanto à inclusividade, a literatura não faz objeção e não nos parece razoável fazer. Contudo, a descentralização do processo de seleção de candidatos não está necessariamente aliada à democratização. Billie (2001) frisa que apenas o processo de descentralização não é suficiente para classificar um partido ou um processo de seleção como mais democrático. Podemos imaginar que processos altamente descentralizados, realizados em instâncias locais do partido, sejam conduzidos por uma liderança única local, o que fere frontalmente a inclusividade. Ou seja, essas duas dimensões - inclusividade e descentralização - não devem ser sobrepostas. Assim, o foco para o estabelecimento de processos que apresentem democracia interna deve estar mais preocupado com a inclusividade de candidaturas e de quem escolhe os candidatos ${ }^{12}$.

\footnotetext{
12 A democracia interna dos partidos poderia ser questionada se encontramos partidos onde a total ausência de controle do processo de nominação fosse constatada. Partidos que não selecionam efetivamente seus candidatos, permitindo que qualquer in-
}

No Brasil, os estudos de seleção de candidatos são muito recentes (ÁLVARES, 2008; BRAGA, 2008; 2009; ARAÚJO \& BORGES, 2012; PERISSINOTTO \& BOLOGNESI, 2009; BRAGA \& BOLOGNESI, 2013). Os estudos que levantaram algumas hipóteses derivadas do arranjo institucional do país, como Mainwaring (1991), Mainwaring e Scully (1997), Samuels (2008), chegaram a conclusões muito focadas ou no comportamento legislativo dos candidatos eleitos, ou numa suposta inexistência de controle por parte dos partidos políticos. Braga $(2008,2009)$ mostrou que a combinação entre sistemas eleitoral proporcional de lista aberta com federalismo, sistema presidencial com foco no executivo e multipartidarismo não acarretam em imediato descontrole dos partidos políticos sobre a representação. Pelo contrário, os partidos desfrutam de mecanismos institucionais que atestam seu controle sobre a formação das listas eleitorais.

Tal como evidenciado por Samuels (2008), o principal problema evidenciado na análise da seleção de candidatos - tanto pelos seus determinantes (o arranjo partidário-eleitoral) quanto por suas conseqüências (o comportamento legislativo) - é que não foi conduzido nenhum estudo que o analise no interior dos partidos, que é onde tais processos ocorrem de fato. Mesmo que aceitemos - o que não é o caso a hipótese de Hazan e Rahat (2007) do determinismo da seleção de candidatos para o comportamento legislativo, em nenhum momento Samuels traz uma discussão de como são formadas as listas no interior dos partidos. A suposição do carreirismo e ambição progressiva como explicação para altos níveis de personalismo ${ }^{13}$ e individualismo dos candidatos está focada essencialmente na esfera dos eleitos e não em estudos realizados com perdedores e vencedores anterior ao crivo das urnas.

Evitando incorrer no mesmo erro, apresentamos aqui uma análise da seleção de candidatos a partir do framework proposto por Hazan e Rahat (2010). Os autores israelenses têm diversas publicações sobre o

teressado se lance como tal, como colocam Siavelis e Morgenstern (2009) e Koop e Bittner (2011), não podem contar com níveis de democracia interna. Os candidatos auto-selecionados são indicadores de que o partido não exerce nenhum tipo de atividade que os leve até a lista. Segundo Samuels (2008, p. 85), a seleção dos candidatos neste tipo de partido estaria nas mãos do próprio candidato.

13 É preciso lembrar que para o autor, o PT não se encaixa neste padrão. Porém chega a este conclusão pelos mesmos caminhos que levam a concluir que os outros partidos são personalistas e não controlam a nominação de candidatos, pelo comportamento legislativo e não pela seleção em si. Configura aqui um erro lógico de tomar a conseqüência pela causa. 
tema, incluindo uma simplificação do modelo de análise publicado em forma de artigo em 2001. Porém, entendemos que o texto de 2010 traz uma visão mais completa e aperfeiçoada para estudarmos a seleção de candidatos. Assim, a seleção de candidatos será analisada descritivamente aqui tendo em vista as quatro dimensões propostas pelos autores.

A primeira dela se refere à inclusividade dos requisitos para candidatura. A imposição de requisitos formais e informais revela o quão inclusivo o partido no que tange às oportunidades para inserção de candidatos. Quanto mais inclusivo nesta dimensão, mais democrático é o partido. A segunda refere-se à inclusividade do selectorate. Feita a ressalva da intensidade de participação dos filiados e a distância em relação destes à elite do partido, quanto maior o envolvimento de atores intermediários na seleção (como delegados de partido), mais democrático é o partido. No sentido oposto, quanto maior o envolvimento de líderes ou predomínio de um líder único na seleção, menos democrático seria. A terceira dimensão se refere à descentralização do processo. Como dissemos antes, essa dimensão não encontra relação íntima com a democracia interna dos partidos políticos. Contudo, entendemos que a descentralização organizativa, quando os partidos mobilizam diversas instâncias para selecionar seus candidatos, revela um importante traço de fortalecimento da máquina organizativa. Por fim, avaliamos as formas de escolha dos candidatos. Candidatos escolhidos por sistemas de votação aproximam os partidos de modelos vistos como democráticos, haja vista que votações sempre supõem a participação de um número razoável de pessoas, mesmo que sejam grupos de lideranças. Por outro lado, sistemas de indicação reforçam práticas clientelísticas e tendem a ligar o candidato às pessoas que tomam a decisão.

\section{QUEM PODE SER CANDIDATO: REQUISITOS FORMAIS E INFORMAIS NOS PARTIDOS POLÍTICOS}

Conforme o modelo apresentado, a primeira variável a ser examinada é a restrição que regras formais e informais podem impor para que o cidadão comum adentre na arena eleitoral. Hazan e Rahat (2010) e Gallagher e Marsh (1988) colocam este elemento como possível responsável por eliminar a maior parte dos aspirantes a candidatos. A partir de um continuum que vai da inclusividade à exclusão, os autores posicionam no pólo mais inclusivo a possibilidade que todo cidadão cumpra os requisitos necessários para ser candidato. No extremo oposto encontramos uma série de restrições que podem ser legais e partidárias, formais ou informais.
A formalidade do processo tem, na maior parte das vezes, pouco peso para barrar os candidatos. Mesmo em países onde a legislação é mais específica (como no caso dos EUA) usualmente só se impõem restrições quanto à idade e a naturalidade do aspirante. As barreiras legais no caso brasileiro restringem-se à lei eleitoral 9.504/97, que estabelece critérios para a elegibilidade de deputados federais: idade mínima de 21 anos, alistamento eleitoral, domicílio eleitoral na circunscrição do candidato, filiação partidária de, no mínimo, um ano antes da data das eleições e não possuir ações penais pendentes. Do ponto de vista formal, os requisitos são facilmente cumpridos pela maior parte dos interessados. O requisito que mais interessa é saber que os partidos detêm o monopólio das candidaturas ${ }^{14}$. Esse primeiro controle permite que os partidos possam impor suas próprias regras para escolher candidatos e, amparados legalmente, os partidos desfrutam de poder para estabelecer estruturas de hierarquia ou horizontalidade e cadeias de controle sob seus candidatos e eleitos.

Mesmo sendo um requisito pouco eficaz para escolher os candidatos, a idade média dos respondentes do survey aplicado foi de 49,9 anos. Uma idade avançada em relação ao requisito legal para a candidatura de deputado federal. De saída, este dado mostra que o requisito legal é fraco e que outras variáveis (como, por exemplo, experiência política), podem ser critérios informais para entrada na lista eleitoral. Outro dado interessante é que mesmo com a lei de cotas prevendo mínimo de $30 \%$ de algum dos sexos nas listas eleitorais, apenas 14,2\% dos entrevistados eram mulheres. Mesmo se olharmos para os dados de todos os candidatos registrados, os números não sobem muito. Conforme Braga e Bolognesi (2013), a proporção de mulheres candidatas para deputado federal em 2010 não passou de 19,1\%. A primeira interpretação poderia sugerir que mulheres candidatam-se pouco para este cargo. Porém, ao observarmos que a média de idade entre as mulheres entrevistadas foi de 47,1 anos, enquanto que a dos homens ficou na casa de 50,4 anos, podemos pensar que alguns poucos anos de experiência política dão maior estofo para as candidaturas masculinas. Este achado é confirmado pelos dados apresentados por Araújo e Borges (2012) que mostram que as mulheres representam o sexo definitivamente minoritário, não chegando a $10 \%$, dentre os "potenciais eleitos". Aquelas candidatas que possuem experiência política e partidária são mais velhas.

\footnotetext{
14 Segundo Freidenberg (2003), apenas El Salvador e Equador permitem candidaturas independentes dos partidos políticos na América Latina.
} 
Adicionalmente a estes requisitos, os partidos podem estabelecer alguma condição formal específica para a candidatura, que vá além daquela estabelecida na lei nacional. Dentre os partidos aqui analisados, apenas o estatuto do PT traz algum adicional neste sentido $^{15}$. PMDB, PSDB e DEM exigem apenas que seus candidatos estejam filiados aos partidos com pelos menos um ano de antecedência para que concorram a cargos eletivos. Já no estatuto petista, é preciso que o candidato "esteja em dia com a tesouraria do partido", ou seja, tenha contribuído regularmente com as finanças da legenda; "assine e registre em cartório o Compromisso Partidário do Candidato Petista", uma forma, mesmo que simbólica, que os líderes do partido podem exercer controle e estabelecer vínculos entre partido e candidato. Um bom exemplo disso é que o conteúdo do "Compromisso Partidário do Candidato Petista" deixa claro que, no caso de vitória eleitoral, o mandato legislativo pertence ao partido e não ao candidato, engrossando o pertencimento do indivíduo à organização (BRAGA \& BOLOGNESI, 2013). De forma análoga, Gallagher (1980) mostra que a maior parte dos partidos da Irlanda exige também uma "declaração de lealdade" (pledge of loyalty), atrelando o mandato e o comportamento legislativo ao partido pelo qual irá disputar a eleição. Esse tipo de adesão simbólica ao partido pode não surtir efeito, sendo apenas mais um critério formal. Contudo, ela pode eliminar alguns aspirantes que não se sintam confortáveis em abrir mão de suas preferências individuais em nome da organização (HAZAN \& RAHAT, 2010, p. 26).

Do ponto de vista da competição política, a inclusão de candidatos sem grandes restrições pode ser uma estratégia visando sucesso eleitoral, na qual os partidos estão preocupados somente em amealhar votos. Por outro lado, requisitos restritivos revelam que o partido está em busca de maior controle da oferta de candidatos e dos seus futuros representantes (idem, p. 20). Portanto, do ponto de vista estritamente formal, apenas o PT está preocupado em ter algum controle inicial sob suas listas, excluindo potenciais candidatos ao exigir contribuição financeira e compromisso partidário. Os outros três partidos analisados são amplamente inclusivos, já que apenas respeitam o previsto em lei.

Abandonando as exigências formais, perguntamos aos candidatos quais seriam, na percepção deles, as principais características que um indivíduo deveria possuir para ser candidato por seu partido ${ }^{16}$.

TABELA 1 - REQUISITOS INFORMAIS PARA CANDIDATURA EM 2010

\begin{tabular}{|c|c|c|c|c|c|}
\hline & \multicolumn{5}{|c|}{ Partido (\%) } \\
\hline & DEM & PMDB & PSDB & PT & Total \\
\hline Conhecimento sobre o funcionamento da "política" & 12,6 & 14,9 & 12,6 & 8,9 & 12,3 \\
\hline Recursos financeiros próprios & 10,3 & 6,9 & 8 & 5,6 & 7,7 \\
\hline Domínio da oratória e retórica política & 8 & 6,9 & 4,6 & 2,2 & 5,4 \\
\hline Possuir bom trânsito no partido & 6,9 & 9,2 & 11,5 & 11,1 & 9,7 \\
\hline Possuir boa densidade eleitoral & 14,9 & 10,3 & 13,8 & 8,9 & 12 \\
\hline Boa reputação pessoal ou prestígio profissional fora da vida política & 21,8 & 21,8 & 21,8 & 8,9 & 18,5 \\
\hline Firmeza ideológica & 10,3 & 12,6 & 9,2 & 22,2 & 13,7 \\
\hline Apoio de movimentos sociais e de base & 6,9 & 5,7 & 11,5 & 18,9 & 10,8 \\
\hline Disponibilidade (tempo) & 8 & 8 & 6,9 & 8,9 & 8 \\
\hline Outras & 0 & 3,4 & 0 & 4,4 & 2 \\
\hline TOTAL & 100 & 100 & 100 & 100 & 100 \\
\hline
\end{tabular}

FONTE: O autor.

Coef. Cont. $0,118=p$ value $<0,0433$

$\mathrm{n}: 351^{17}$

\footnotetext{
$\overline{16}$ A pergunta feita aos candidatos foi a seguinte: "Quais as três principais características que o senhor julga serem as mais importantes para ser candidato a Deputado Federal?". Os entrevistadores fizeram uso de barras de probes para esclarecimento do conteúdo das respostas.

17 O n da amostra aqui salta de 120 indivíduos e sobe para 351 porque pedimos que cada respondente indicasse três características que o mesmo julgava importante. Assim, estão contabilizadas aqui três observações para cada entrevistado, sendo que nove delas não foram respondidas.
}

15 Artigo 128 do estatuto do PT. 
Como mostra a tabela 01 acima, podemos ver que as exigências informais são bem distribuídas entre os partidos. Na análise dos resíduos padronizados, apenas os três valores destacados apresentaram números acima de 1,96 ou abaixo de $-1,96$. (valores que cercam o limite crítico dos resíduos). $\mathrm{O}$ uso dos resíduos aqui revela a diferença entre o observado e o esperado do comportamento de uma variável em determinado grupo - neste caso, partido político. Resíduos acima de 1,96 apontam que aquele valor está acima do esperado, bem como o contrário, para valores abaixo de $-1,96$.

Em primeiro lugar, notamos que todos os valores que tiveram resíduos significativos referem-se ao PT. Todos os demais partidos não apresentam diferenças significativas entre os critérios que os candidatos acreditam ser importantes para fazer parte das listas eleitorais, ou seja, estão distribuídos de forma bastante homogênea entre eles. Em segundo lugar, a exigência possuir "boa reputação pessoal ou prestígio fora da vida política" apresentou resíduos, para o PT, no valor de $-2,1$. Isso mostra que os candidatos petistas, em relação aos dos outros partidos, percebem esta como uma característica significativamente menos importante para candidatura. Interessante notar também o fato dos candidatos petistas darem pouco valor à experiência extra-política, "possuir bom trânsito no partido" atingiu valores muito parecidos para todos os partidos. Para resumir: o fato de valorizarem pouco a experiência pessoal não faz com que os candidatos do PT apresentem "bom trânsito no partido" como uma exigência que difere dos outros partidos. Isto talvez seja melhor explicado a seguir pelos resíduos positivos.

Por outro lado, "possuir firmeza ideológica" apresentou resíduos padronizados na casa de 2,2, revelando que os candidatos deste partido creditam à ideologia um papel acima do esperado para lançaremse no pleito eleitoral pelo PT. Por fim, ter "apoio de movimentos sociais e de base" atingiu o valor de 2,3 nos resíduos, mostrando ser a exigência informal com valores muito superiores àqueles apresentados pelos outros partidos. Ou seja, apenas para o PT ter este tipo de apoio destacou-se além do esperado na amostra de observações. Esperaríamos que a oposição automática à "boa reputação pessoal", seria a valorização da partidária. Porém, no caso específico, os dados sugerem que esta diferença está nas bases que fundamentam os partidos políticos e, mais especificamente para o PT, nos movimentos sociais e na ideologia.

Aplicando os achados ao modelo de Hazan e Rahat (2010), o continuum da inclusividade da candidatura ficaria como o abaixo ${ }^{18}$ :

\section{FIGURA 1 - INCLUSIVIDADE NA CANDIDATURA}

\begin{tabular}{|c|c|c|}
\hline \multirow[t]{2}{*}{ Inclusividade } & & Exclusão \\
\hline & DEM / PMDB / PSDB & PT \\
\hline $\begin{array}{l}\text { Todos os } \\
\text { Cidadãos }\end{array}$ & $\begin{array}{l}\text { Membros } \\
\text { do Partido }\end{array}$ & $\begin{array}{c}\text { Membros } \\
\text { do Partido } \\
+ \\
\text { Exigências } \\
\text { Adicionais }\end{array}$ \\
\hline
\end{tabular}

FONTE: o autor.

O PT foi o único partido que apresentou critérios formais e informais, diferentes dos demais, para que o filiado pudesse concorrer ao cargo de deputado federal nas eleições de 2010. Os três outros partidos encontram-se à direita do ponto 'membros do partido' no continuum pois todos exigem, em alguma medida, requisitos informais para a candidatura. $\mathrm{O}$ que coloca o PT no ponto mais extremo de exclusão é a significativa diferença apresentada nos resíduos padronizados em relação ao esperado comportamento das variáveis em todos os partidos.
Hazan e Rahat (2010) lembram que partidos orientados eleitoralmente, como partidos cartel e catchall, tendem a ser menos rigorosos nos critérios de candidaturas, visto que esses tipos de partidos estão preocupados essencialmente com o sucesso eleitoral. O estudo de Suri (2007) sobre partidos do sul da Ásia chega à mesma conclusão. Partidos do tipo cartel e

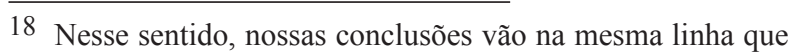
Braga (2008) aponta em seu trabalho.
} 
catch-all de países como Índia e Paquistão, apresentaram o mesmo comportamento. Já partidos de orientação ideológica à esquerda, como o caso do PT - do Partido Socialista Belga ou do Partido Comunista Italiano ${ }^{19}$ - (OBLER, 1974; HAZAN \& RAHAT, 2010), tendem a impor uma quantidade maior de regras para que os membros sejam candidatos. Essa estratégia, segundo Katz (2001), privilegia um maior equilíbrio entre as arenas eleitorais e partidárias (public face of the party e party on the ground, para utilizar a terminologia do autor).

A organização de grandes partidos de esquerda, como mostra Panebianco (2005), privilegia a organização partidária desde sua fundação. Partidos de trabalhadores tendem a contar com recursos parcos fora das legendas partidárias, o que fortalece $(e$, ao mesmo tempo, constrange) os membros do partido a possuir laços de lealdade mais densos. Já partidos legislativos e orientados de forma ideologicamente oposta ou de centro, tendem a lançar mão de membros que portam recursos advindos de outras esferas que não só o partido, o que torna mais difícil a operacionalização de constrangimentos para filiação e candidatura. Podemos pensar que, à primeira vista, PMDB, PSDB e DEM aproximar-se-iam mais deste tipo de partido (AMES \& POWER, 2007). Especificamente sobre o PT, vemos que mesmo diante de mudanças importantes em sua estrutura organizacional ao longo dos anos (MARENCO DOS SANTOS \& SERNA, 2007; AMARAL, 2011), o partido mantém traços de sua origem e ligações com as bases sociais.

Além da constatação acerca dos modelos de partido e as consequiências para a seleção de candidatos, o principal achado geral é que, diferente do que Mainwaring (1991) e Samuels (2008) afirmam acerca do controle sobre a seleção de candidatos, os partidos costumam exigir algumas características importantes para que os pleiteantes integrem suas listas. Mesmo que as evidências mostrem que a "boa reputação pessoal ou prestígio profissional fora da vida política" predomine dentre as exigências para candidatura, (conforme a tabela 01) e esta seja uma condição extrapartidária, a presença deste requisito reafirma a tese de Braga (2008) de que os partidos políticos controlam minimamente a escolha de candidatos desde a imposição de elementos informais para a candidatura. Caso isso não ocorresse, todos os partidos estariam exatamente

\footnotetext{
19 Fique claro que nosso objetivo aqui não é fazer uma comparação com partidos de mesma orientação ideológica de outros países, os exemplos citados são somente ilustrativos de outros achados semelhantes aos nossos.
}

acima do ponto "filiados" na reta de inclusividade, cumprindo apenas as exigências legais.

\section{III.1 Exigências adicionais.}

Exigências adicionais podem ser impostas tanto no estatuto do partido ou nas leis partidárias, quanto apresentarem-se informalmente, privilegiando este ou aquele grupo de pessoas. Dinheiro, tempo, carreiras flexíveis, apoio de bases sociais e/ou geográficas são elementos que dão volume às candidaturas através de preconceitos indiretos. Esse background social dos aspirantes é capaz de atender ou não às demandas dos responsáveis por fazer a seleção, eliminando indiretamente grupos específicos que não atendam aos objetivos do partido ou ao eleitorado (NORRIS \& LOVENDUSKI, 1997). Porém, boa parte da literatura sobre recrutamento político e seleção de candidatos destaca a figura do candidato à reeleição como central para o sucesso eleitoral (RUSH, 1969; PERISSINOTTO \& BOLOGNESI, 2010; BRAGA; VEIGA; MIRÍADE, 2009; HAZAN \& RAHAT, 2010).

É de se esperar que incumbents desfrutem de privilégios dentre as listas partidárias por razões lógicas. Em primeiro lugar, eles já passaram em alguma vez pela seleção que todos os desafiantes estão experimentando. Em segundo lugar, contam votos de eleitores já conquistados em eleição ou eleições anteriores, o que os garante uma boa moeda de troca frente aos líderes partidários. Em terceiro lugar, candidatos à reeleição podem contar com plataformas de campanha mais sólidas, apresentado em seu currículo sua atuação legislativa para conquista de votos. Por fim, a soma destes recursos reverte em apoio de líderes políticos, da mídia e recursos financeiros de apoiadores de campanha (HAZAN \& RAHAT, 2010).

Se por um lado a presença de candidatos à reeleição pelo mesmo partido pode indicar estabelecimento de laços de lealdade ${ }^{20}$, a monotonia nas listas de partido pode prejudicar a imagem do mesmo frente aos eleitores. É necessário um equilíbrio entre desafiantes e incumbents para garantir boa quantidade de votos e ao mesmo tempo promover a renovação no partido. No Brasil a chamada "candidatura nata" 21 , vigente

\footnotetext{
20 Entendemos lealdade aqui nos termos colocados por Siavelis e Morgenstern (2009), onde os autores frisam que as lealdades se dão à longo prazo e em relação, principalmente, ao selectorate.

21 A candidatura nata era um direito que os candidatos que disputavam a reeleição gozavam no Brasil até esta data. Qualquer candidato que estivesse disputando mais de uma vez consecutiva o mesmo cargo era automaticamente inserido na lista eleitoral de seu partido, independente das vontades ou regulações da legenda pela qual disputava.
} 
até 2002, promovia automaticamente os detentores de mandato representativo a candidatos, sem que o partido pudesse intervir. Esse traço institucional certamente serviu para asseverar o papel dos candidatos à reeleição nos partidos ao longo dos anos.
Desse ponto de vista, todos os quatro partidos apresentaram valores muito semelhantes quanto à quantidade de incumbents e quanto à quantidade média de vezes que cada um de seus candidatos foi candidato pelo partido antes das eleições daquele ano.

TABELA 2 - PROPORÇÃO DE CANDIDATOS À REELEIÇÃO POR PARTIDO EM 2010

\begin{tabular}{|l|c|c|c|c|c|}
\hline & \multicolumn{5}{|c|}{ Partido (\%) } \\
\cline { 2 - 6 } & PT & PMDB & DEM & PSDB & Total \\
\hline No Incumbent & 82,9 & 83,2 & 85,9 & 85,8 & 84,2 \\
Std. Res. & $-0,3$ & $-0,2$ & 0,3 & 0,3 & 15,8 \\
Incumbent & 17,1 & 16,8 & 14,1 & 14,2 & 1144 \\
Std. Res. & 0,6 & 0,4 & $-0,6$ & $-0,7$ & 100 \\
Total & 339 & 340 & 191 & 274 & 100 \\
\end{tabular}

Fonte: TSE (2012). Sig. Coef. Contingência $=p$ value $>0,500$.

Como mostra a tabela 02 acima, não há diferença significativa entre os partidos na quantidade de candidatos à reeleição. Todos os quatro partidos usam do potencial destes candidatos para montarem suas listas eleitorais. Como mostramos, a média de incumbents está na casa de $15,8 \%$, com um mínimo de $14,1 \%$ para o caso do DEM e um máximo de $17,1 \%$ para o PT em 2010.

Poderíamos imaginar então que os partidos estabeleçam a lealdade exigindo que os candidatos concorram por várias eleições ao longo de suas filiações partidárias. Isso poderia estar relacionado ao fato de que o candidato que assume o mandato pela primeira vez terá privilégios para se recandidatar por quantas vezes quiser. Porém, diante da relativamente baixa quantidade de candidatos à reeleição (tal como exposto na tabela 02), podemos pensar que esse número de candidaturas é também um requisito específico. Norris e Lovenduski (1997) colocam como fundamental a "persistência" como recurso do sucesso eleitoral. Rush (1969) frisa que a experiência eleitoral prévia é um dos mais importantes critérios para que os indivíduos sejam escolhidos para disputar as eleições, sendo um traço que os líderes partidários identificam como relevante na medida em que tomar conhecimento do cotidiano da política é fundamental. Para tanto, perguntamos aos candidatos: "O senhor (a) poderia nos dizer quantas vezes foi candidato a Deputado Federal pelo seu partido?", as respostas seguem abaixo na tabela 03 .

TABELA 3 - ANÁLISE DESCRITIVA DA QUANTIDADE DE VEZES COMO CANDIDATO A DEPUTADO FEDERAL POR PARTIDO POLÍTICO EM 2010

\begin{tabular}{|lcc|c|c|c|c|c|c|}
\hline Partido Político & Mean & $\mathbf{N}$ & Std. Deviation & Median & Minimum & Maximum & Range \\
\hline DEM & 1,43 & 30 & 1,906 & 1 & 0 & 7 & 7 \\
PMDB & 1,03 & 30 & 1,129 & 1 & 0 & 4 & 4 \\
PSDB & 1,2 & 30 & 1,4 & 1 & 0 & 4 & 4 \\
PT & 1,07 & 30 & 1,388 & 1 & 0 & 6 & 6 \\
Total & 1,18 & 120 & 1,472 & 1 & 0 & 7 & 7 \\
\hline
\end{tabular}

FONTE: O autor.

Como podemos notar na tabela acima, todos os partidos possuem médias muito próximas quanto à quantidade de vezes que seus candidatos concorreram a cargos eletivos por seus partidos, antes das eleições de 2010. Apesar das médias serem muito próximas e do teste de análise de variância (ANOVA) não ter resultado em significância estatística, alguns dados merecem ser sublinhados. Em primeiro lugar, notemos 
que o PMDB é o partido com menor desvio padrão para este dado, o que mostra que os seus candidatos possuem comportamento mais homogêneo e em torno da média do que os outros dois partidos. Isso se reflete também na amplitude do dado. Já PSDB e PT possuem médias e desvios padrão muito próximos, sendo que a diferença recai na amplitude, sugerindo que alguns candidatos petistas precisam persistir mais para lograr candidaturas do que os peessedebistas. O DEM possui uma média mais alta de número de candidaturas anteriores. Porém, o desvio padrão é também elevado, revelando que apenas alguns poucos indivíduos ajudam a ampliá-la. Ainda assim, é notável que o partido tenha dentre seus candidatos alguns que se lançaram sete vezes pelo partido. Do ponto de vista do estabelecimento de lealdades, parece que o PT e DEM possuem uma maior capacidade de realizá-la. Destaquese que o PT que consegue imprimir persistência a uma maior quantidade de candidatos.

Como um todo, essa primeira seção na qual apresentamos os requisitos para candidatura, aponta o PT como o partido mais excludente no tocante a quem pode ser candidato, enquanto os outros três partidos cumpriram as exigências previstas na legislação eleitoral e algumas exigências adicionais mais homogêneas entre si. Sobre as exigências adicionais, destacamos a importância da presença de incumbents nas listas de partido e também a homogeneidade da distribuição da proporção deste tipo de candidato entre os analisados. Por fim, o possível estabelecimento de lealdade entre partido e candidato estaria na dimensão da persistência, porém as diferenças foram muito pequenas para que possamos traçar uma distinção entre as quatro agremiações.

Dos critérios que Freidenberg (2003) aponta para a democratização, a abertura para a participação estaria muito mais atrelada aos outros três partidos do que ao PT. Os aspirantes petistas precisam cumprir tanto exigências formais mais rígidas, quanto informais mais sólidas do que seus colegas, o que coloca, neste critério, o PT como o partido menos democrático entre eles.

\section{O SELECTORARE: QUEM SELECIONA OS CANDIDATOS}

O termo selectorate foi cunhado inicialmente por Paterson (1967) para designar o corpo de indivíduos, instituições ou instâncias burocráticas que detêm o poder de influenciar e/ou determinar quem serão os candidatos dos partidos nas eleições que seguem. Em seu estudo sobre os partidos britânicos (mais especificamente o Labour e o Conservative), o autor levanta uma série de possíveis selectorates que vão desde sindicatos ligados aos partidos, até associações locais que influenciam a composição final das listas. É importante notar que uma tradução livre do termo para "selecionador", "selecionadores" ou "corpo selecionador" reduziria a dimensão do conceito: falar em selecionador ou selecionadores acaba limitando o escopo da análise a um grupo de pessoas de qualquer natureza que participam em algum momento da escolha dos candidatos. A intenção em manter o termo selectorate é designar, por outro lado, o seu componente abstrato, deixando-o permeável para a participação de pessoas, instituições ou um misto das duas coisas.

Rahat e Hazan (2001) afirmam que o selectorate é o filtro mais importante na seleção de candidatos. Outros autores como Gallagher e Marsh (1988) 22 e também Hazan (2002) notam que é justamente com este elemento que as análises devem se preocupar. A definição de Hazan e Rahat (2010, p.33) de selectorate é a seguinte: "Ao tratarmos de partidos políticos em geral e seleção de candidatos especificamente, o 'selectorate' é o corpo que seleciona os candidatos do partido para o cargo público ${ }^{23 " .}$

Siavelis e Morgenstern (2009) mostram que é em relação a este elemento que em geral as lealdades são construídas. Candidatos selecionados por órgãos partidários tendem a ser mais leais ao partido, enquanto os candidatos nomeados por organizações associadas ao partido tendem a ser leais antes às organizações do que ao partido em si; candidatos auto-selecionados sem que haja a participação de um selectorate - se comportam de forma independente em sua vida política, enquanto candidatos escolhidos por um líder único devem sua lealdade somente a ele. Da mesma forma que as conseqüências podem ser individualizadas em relação ao comportamento dos escolhidos, o selectorate é também o principal indicador para que possamos auferir níveis de democracia interna dos partidos políticos. É através dele que podemos verificar quais são os atores envolvidos, como se dá a distribuição de poder no partido e como os envolvidos garantem (ou deixam de garantir) a representatividade nas listas eleitorais.

Em tese, o selectorate age de acordo com uma complexidade de cálculos que levam em conta a garantia do sucesso eleitoral (como vimos com a proporção de incumbents na tabela 02), o equilíbrio de forças no interior do partido e a imagem que o partido

\footnotetext{
22 Gallagher e Marsh utilizam participação como sinônimo de inclusividade, mas na prática o significado da dimensão é exatamente o mesmo.

23 When speaking of political parties in general, and candidate selection in particular, the selectorate is the body that selects the party's candidates for public office. Tradução do autor.
} 
pretende projetar durante as campanhas eleitorais. Um indicador simples para que possamos mensurar essa complexidade de cálculos dos líderes do partido é analisar o selectorate a partir de um continuum de inclusividade, do mesmo modo como fizemos com a análise dos requisitos para candidatura. Seguindo o modelo de Hazan e Rahat (2010) temos que colocar no pólo mais inclusivo os candidatos que seriam selecionados por todos os eleitores habilitados naquela eleição. No pólo extremo oposto, um único líder seria responsável pela seleção de todos os candidatos. Num ponto de baixa inclusividade, os filiados do partido seriam responsáveis por selecionar os candidatos. O ponto de equilíbrio seria aquele no qual os delegados do partido realizam a seleção. $\mathrm{O}$ altamente exclusivo se representa pela escolha feita pela elite partidária. A figura 02 que segue abaixo apresenta o modelo teórico da inclusividade no selectorate.

FIGURA 2 - SELECTORATE PARTIDÁRIO

\begin{tabular}{|c|c|c|c|c|}
\hline Eleitores & Filiados & $\begin{array}{l}\text { Delegados } \\
\text { do Partido }\end{array}$ & $\begin{array}{c}\text { Elite } \\
\text { Partidária }\end{array}$ & Líder Único \\
\hline Inclusão •- & & & & $\longrightarrow$ Exclusão \\
\hline
\end{tabular}

FONTE: o autor.

O problema é que modelos teóricos dificilmente correspondem à realidade que encontramos nos partidos políticos. A lista de candidatos que é homologada na convenção estadual do partido, no caso do Brasil, pode ser composta pela escolha de diferentes tipos de selectorate, combinando as formas com que isso ocorre. Hazan e Rahat (idem), descrevem três possíveis combinações complexas entre os selectorates para realizar a seleção de candidatos: i) método sortido; ii) multi-estágio e; iii) método balanceado.

- Método sortido: neste método diferentes candidatos passam por diferentes selectorates que distinguem em relação ao seu nível de inclusividade. Por exemplo, uma parte dos candidatos é selecionada por delegados do partido, enquanto outra parte é escolhida por um colégio de líderes.

- Método multi-estágio: neste método o mesmo grupo de candidatos passa por mais de um selectorate durante a composição da lista. Podemos imaginar uma situação onde num primeiro momento os filiados do partido apresentem uma lista que sofrerá cortes e será filtrada por um líder único do partido.

- Método balanceado: aqui o mesmo grupo de candidatos passa por dois tipos de seleção que são levadas em conta para, a partir do peso de cada processo de seleção, ter como resultado uma lista balanceada. Podemos pensar que a lista seria composta, por exemplo, por candidatos selecionados pelo voto de delegados do partido e ao mesmo tempo pelo voto do colégio de líderes, tendo cada um dos selectorates tendo um peso diferente na escolha.

A figura 03 abaixo, reproduzida a partir de Hazan e Rahat (idem) representa graficamente como cada um destes métodos funcionaria no interior dos partidos políticos. 
FIGURA 3 - REPRESENTAÇÃO GRÁFICA DOS MÉTODOS COMPLEXOS DE SELEÇÃO DE CANDIDATOS

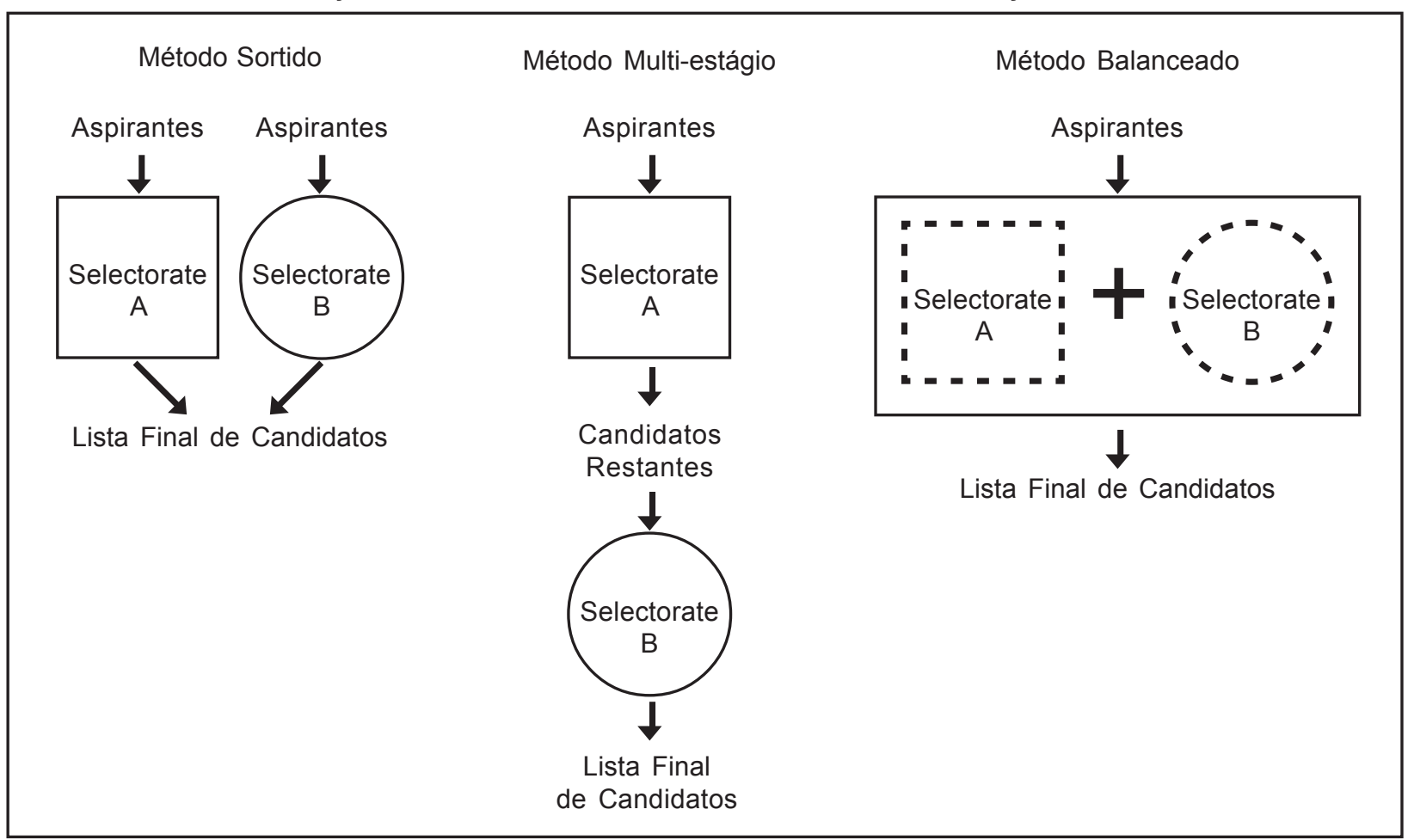

FONTE: o autor.

Nos partidos aqui abordados, todas as respostas evidenciam que o método de seleção adotado foi o sortido. O mesmo corpo de candidatos foi selecionado por diferentes selectorates com níveis desiguais de inclusividade. Não houve respostas que nos levem a acreditar que o mesmo candidato passou por mais de um método de seleção ou que dois selectorates distintos atuaram de forma balanceada para compor as listas. A tabela 04 a seguir aponta por quais métodos os respondentes afirmaram terem sido selecionados. Para atribuir esta resposta, perguntou-se aos candidatos o seguinte: "Tendo em vista sua experiência durante o processo de seleção de candidatos a deputado federal em seu partido, o senhor(a) diria que o processo é feito por:".

TABELA 4 - QUEM SELECIONOU OS CANDIDATOS NOS PARTIDOS EM 2010

\begin{tabular}{|c|c|c|c|c|c|c|}
\hline & & \multicolumn{4}{|c|}{ Partido Politico (\%) } & \multirow[b]{2}{*}{ Total } \\
\hline & & DEM & PMDB & PSDB & PT & \\
\hline Filiados do Partido & & 11,1 & 28,6 & 22,2 & 17,9 & 20,0 \\
\hline Std. Res. & & -1 & 1 & 0,3 & $-0,3$ & \\
\hline Delegados do Partido & & 7,4 & 0,0 & 18,5 & 67,9 & 23,6 \\
\hline Std. Res. & & $-1,7$ & $-2,6$ & $-0,5$ & 4,8 & \\
\hline Líderes do Partido & & 55,6 & 60,7 & 51,9 & 14,3 & 45,5 \\
\hline Std. Res. & & 0,8 & 1,2 & 0,5 & $-2,4$ & \\
\hline Líder Único do Partido & & 25,9 & 10,7 & 7,4 & 0,0 & 10,9 \\
\hline Std. Res. & & 2,4 & 0 & $-0,6$ & $-1,7$ & \\
\hline & $\mathrm{n}$ & 27 & 28 & 27 & 28 & 110 \\
\hline & Total & 100 & 100 & 100 & 100 & 100 \\
\hline
\end{tabular}

FONTE: $o$ autor $-\mathrm{n}$ missing $=10^{24}$

Coef. Contigência 0,568

$p$ value $<0,000$

\footnotetext{
24 Boa parte deste número de missing refere-se aos candidatos
}

que afirmaram terem sidos selecionados por organizações externas aos partidos políticos, como associações profissionais, de 
Como no Brasil a seleção de candidatos é monopólio legítimo dos partidos políticos, não é possível que eleitores participem do processo. De saída, a legislação já torna a seleção de candidatos menos inclusiva do que poderia ser. Assim, na prática, o pólo mais inclusivo aqui é a escolha realizada por filiados do partido. Essa opção de selectorate foi pouco mobilizada por todos os partidos e, quando ocorreu, não apresentou diferenças significativas entre os eles. Mesmo no caso do PMDB onde $28,6 \%$ dos candidatos afirmaram terem sido escolhidos por este selectorate, a diferença não foi tão grande para que os resíduos padronizados ficassem acima de 1,96. Majoritariamente, os quatro partidos optaram por escolherem seus candidatos através de líderes, $45,5 \%$ das respostas indicaram que chegaram até a lista final de candidatos pelas mãos destes.

Chamam a atenção os resíduos negativos do PT para este caso. $\mathrm{O}$ valor de $-2,4$ indica que o partido difere significativamente de seus pares quanto a mobilizar os líderes para a formação das listas. Por outro lado, o mesmo PT apresentou resíduos muito altos, na casa de 4,8, quando a opção de escolha de candidatos estava atribuída aos delegados do partido, onde $67,9 \%$ das respostam apontaram neste sentido. O oposto ocorre com o PMDB, onde os resíduos negativos de 2,6 atestam a nulidade na mobilização deste método para selecionar candidaturas. O DEM apresentou resíduos positivos de 2,4 para a seleção por líder único do partido. $25,9 \%$ de seus candidatos foram selecionados por este selectorate. Mesmo admitindo que este não foi o principal método usado no partido - já que outros $55,6 \%$ de candidatos afirmaram terem sido selecionador por líderes partidários - é importante notar que o DEM é o que mais se valeu desse escrutínio. Por fim, o PSDB apresentou uma distribuição equilibrada em relação à distribuição dos selectorates. Tendo seus candidatos selecionados majoritariamente por líderes do partido, (de acordo com 51,9\% das respostas) os outros pontos de inclusividade na seleção não mostraram diferenças reais em relação aos outros partidos.

Mais uma vez, o debate com os autores brasilianistas, essencialmente Mainwaring (1991) e Samuels (2008) - que, como vimos na primeira seção, atribuem ao sistema eleitoral e partidário brasileiro os motivos do baixo controle dos partidos sobre seus candidatos - mostra que tal afirmação não encontra pé na realidade quando tratamos de seleção de candidatos. A evidência contundente de que a maior parte dos candidatos é selecionada por líderes do partido mostra que existe sim algum mecanismo de controle (Braga, 2008). Em segundo lugar, a participação de filiados e delegados de partido é bastante alta, apontando que não há somente controle, mas que órgãos formais das legendas atuam diretamente num processo central como formação de listas. Ou seja, além de controle, existe distribuição de poder entre as "camadas" que compõem o partido. Em alguns partidos esse equilíbrio é mais proporcional, como no caso de PT e PSDB, enquanto nos outros a balança tende a pesar mais para os líderes.

Voltando nossa atenção para os valores mais altos das respostas, a presença da multiplicidade de selectorates dificulta uma classificação linear no continuum de inclusividade. Por exemplo, no caso específico do PSDB destas eleições (nas quais a maior parte dos candidatos foi selecionada por líderes do partido), não podemos excluir o fato de que boa parte dos que chegaram ao final da lista partidária foram escolhidos por filiados e delegados. Para solucionar este problema analítico da inclusividade, Hazan e Rahat (2010), propõem o uso de uma escala de vinte e cinco pontos onde podemos classificar métodos complexos de seleção de candidatos. Abaixo a reprodução da escala com a distribuição dos partidos de acordo com os dados disponíveis na tabela acima.

FIGURA 4 - DISTRIBUIÇÃO DOS PARTIDOS NO CONTINUUM DE INCLUSIVIDADE DO SELECTORATE NAS ELEIÇÕES DE 2010.

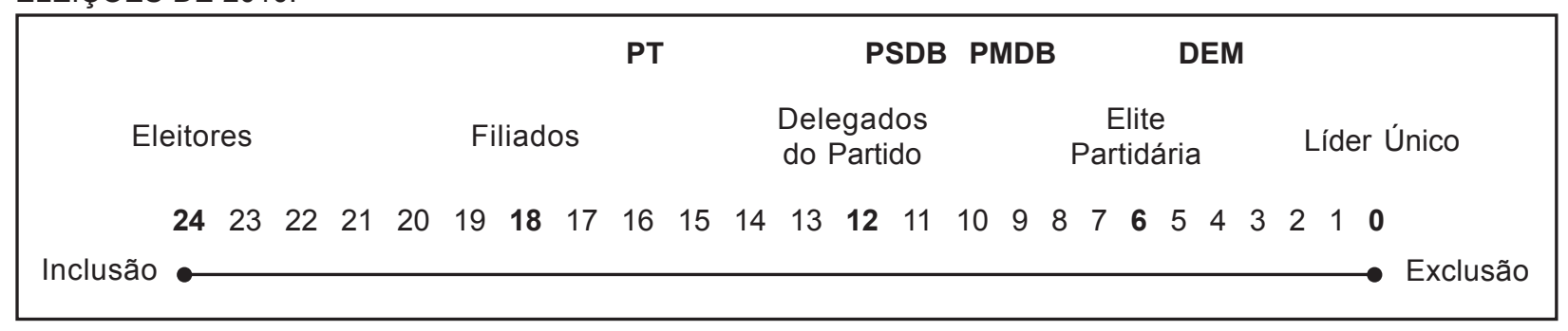

Fonte: Elaboração do autor, a partir do survey e de Hazan e Rahat (2010, p.49)

classe ou sindicatos. Para fins de análise, esse dado será aqui tratado como missing e será retomado quando discutirmos a descentralização social da seleção de candidatos. 
A escala proposta possui dois postulados para o posicionamento dos partidos no continuum. O primeiro, que os intervalos entre cada selectorate representam o espaço para seleções complexas, podendo ser do tipo sortida, balanceada ou multi-estágio. A cada seis pontos na reta podemos aproximar os métodos de atuação do selectorate de acordo com a complexidade e multiplicidade de selectorates que cada partido contou. O segundo, que o posicionamento dos partidos no continuum é feito de acordo com a predominância de um selectorate sobre outros. Por exemplo, no caso do PT a maior parte dos candidatos afirmou ter sido selecionada por delegados do partido. Se utilizássemos apenas este critério, o PT estaria posicionado exatamente acima do ponto doze. Como a participação de filiados foi também presente para este partido, o PT ficou no ponto mais inclusivo da reta. O PSDB apresentou alguns pontos de maior exclusão, mobilizando, na maior parte das vezes, líderes, mas contando também com delegados de partido e filiados numa forma bastante sortida de atuação do selectorate. Portanto, adotamos o critério da predominância de líderes para este partido e aproximamos o partido do pólo mais inclusivo levando em conta as outras duas formas de seleção apresentadas. Já o DEM foi posicionado no ponto mais excludente em relação aos outros partidos, posto que a maior parte da seleção é realizada pela combinação de lideranças do partido e de um líder único, deixando pouquíssimo espaço para a participação de delegados e filiados do partido.

O PMDB merece uma interpretação mais detida. $\mathrm{O}$ partido não apresentou seleção por delegados. Por outro lado, a combinação entre predominância de seleção realizada por líderes do partido (incluído aqui seleção por líder único) e seleção por filiados, aproxima o partido do modelo cartel de organização. Katz (2001) enfatiza a substancial separação entre líderes e base do partido para definição do modelo cartel de partido e suas conseqüências para a seleção de candidatos. $\mathrm{O}$ PMDB aproxima-se deste modelo ao anular completamente a possibilidade de existências de intermediários capazes de exercer algum controle efetivo sobre a elite do partido. A participação de filiados é descolada de meios que empoderam os membros ordinários do partido, como os delegados. A tese da cartelização da seleção fica muito evidente no caso peemedebista, onde não há possíveis desafiantes para o poderio das elites (idem). Deste modo, os filiados possuem apenas um poder pulverizado, não sendo capazes de determinar em nada a seleção de candidatos. Essa abordagem nos levou a posicionar o PMDB num ponto mais exclusivo do que o PSDB, por exemplo, aceitando a tese de que a separação absoluta entre elite partidária e filiados aumenta ainda mais o espaço de manobra das elites do partido.
Fica muito claro aqui que os partidos controlam a seleção de candidatos de formas diferentes, mas todos exercem algum controle. Não é preciso retomar, mais uma vez, as teses dos brasilianistas, mas é patente que o sistema eleitoral e o sistema partidário encontram um anteparo quando os partidos exercem funções de escopo interno. Nesse sentido, os partidos políticos aqui devem ser entendidos como variáveis intervenientes ${ }^{25}$ no processo de seleção de candidatos. Em 69,1\% das respostas os candidatos afirmaram terem sido escolhidos por líderes do partido ou por delegados. Estas duas instâncias excluem os pólos de inclusividade onde o estabelecimento de lealdades é mais enfraquecido. Siavelis e Morgenstern (2009) e Hopkin (2001) mostram que a seleção quando realizada por larga participação de filiados tende a produzir candidatos que atendem ao eleitor médio do partido e são incapazes de identificar para quem devem prestar contas de suas atividades políticas e seu possível mandato. Hopkin é claro ao notar que a seleção por membros sem poder real dentro dos partidos pode levar a uma conseqüência inesperada oposta, onde os candidatos adquirem autonomia total e não se responsabilizam em relação a nenhum órgão do partido. Um fenômeno parecido ocorreria com a predominância de seleção de candidatos realizada por um único líder: os candidatos não teriam incentivos para direcionar suas lealdades para o partido como organização, mas sim para o líder que foi responsável pela sua chegada até a lista eleitoral. Qualquer mudança na orientação do líder, mesmo que vá contra o partido como instituição, teria efeitos sobre os candidatos assim selecionados (SIAVELIS \& MORGENSTERN, 2009).

Do ponto de vista dos níveis de democracia interna, a inclusividade do selectorate, baseado nos critérios de Freidenberg (2003), revela que o PT é o partido mais democrático entre os quatro abordados. Além disso, não incorre nos possíveis efeitos inesperados que a seleção que mobiliza demais os filiados pode apresentar. Por outro lado, o DEM apresentou o perfil menos democrático, focando seu processo de seleção majoritariamente nos líderes do partido - quando não num líder único. Isso nos leva a entender que o Democratas está mais preocupado com as relações que os candidatos irão estabelecer individualmente com seus líderes do que com o partido em si. O mesmo ocorre com o PMDB, que adota um modelo cartelizado de seleção, dando nulidade de voz para agentes

\footnotetext{
25 Utilizamos a definição de variável interveniente proposta por Rosenberg (1976,p. 71): “A variável interveniente [...] é encarada como conseqüência da variável independente (aqui o sistema eleitoral e partidário) e como determinante da variável dependente (a seleção de candidatos)".
} 
intermediários do partido e focando nos laços entre líderes e candidatos sua seleção. A diferença é que o PMDB não utilizou tão largamente a indicação de um líder único para apontar os candidatos. O PSDB apresenta níveis mais moderados de democracia, dando liberdade para a participação de delegados e filiados. Mas, ao mesmo tempo, preservando o controle do processo através de seus líderes.

Não resta dúvida de que o selectorate é a dimensão mais importante da seleção de candidatos em qualquer partido político. Contudo, a centralização do processo pode ter conseqüência para os níveis de democracia interna e, principalmente, para a representação de minorias nos partidos políticos. Volto a lembrar que a dimensão do conteúdo não pode ser utilizada para a classificação dos partidos em mais ou menos democráticos. É possível apenas que se fale em conseqüências nesse sentido. Assim, não basta que as legendas sejam capazes de controlar o processo por meio de líderes e de delegados, mas que as escolhas tenham também conteúdo democrático. Deste modo, a (des) centralização da seleção é fundamental para garantir à lista eleitoral a participação de grupos minoritários como mulheres, minorias étnicas e religiosas.

\section{DESCENTRALIZAÇÃO: ENTRE TERRITÓRIO E REPRESENTAÇÃO POLÍTICA}

A descentralização talvez seja o tema de maior controvérsia nos estudos de seleção de candidatos. Há três tipos de descentralização possíveis. O primeiro é a descentralização territorial, no qual os partidos políticos escolhem seus candidatos de acordo com o grau de participação da executiva nacional no processo de seleção (RAHAT \& HAZAN, 2001). Países federados, como o Brasil, tendem a escolher seus candidatos de forma descentralizada, dando maior autonomia às instâncias regionais dos partidos. Em segundo lugar, a participação de múltiplos selectorates no mesmo processo de seleção indica descentralização organizativa. Candidatos que experimentam individualmente ser escolhidos por mais de um selectorate refletem que o partido descentraliza organizativamente seus órgãos internos para esta função. A descentralização organizativa pode ou não estar associada à territorial. Podemos pensar num processo de seleção local no qual todos os candidatos são escolhidos por um único selectorate, sem coparticipação de nenhum tipo (balanceada, sortida ou multi-estágio) (HAZAN \& RAHAT, 2010) ${ }^{26}$. Em terceiro lugar, a descentralização pode ser social, quando há participação de grupos associados ao partido ou ações afirmativas que garantem a representatividade de grupos minoritários.

No caso do Brasil, todos os partidos desfrutam de um grau de descentralização territorial alto. Isso ocorre, em primeiro lugar, porque a legislação obriga que os candidatos a deputado federal sejam nomeados pelas executivas estaduais dos partidos políticos e que os candidatos possuam domicílio eleitoral em seus distritos com pelo menos um ano de antecedência às eleições (BRAGA, 2009). O segundo motivo é que num país com a dimensão territorial brasileira e um número tão elevado de candidatos - nas últimas eleições foram mais de 4.800 para deputado federal segundo o Tribunal Superior Eleitoral (TSE) - é impossível que as executivas nacionais controlem o processo de escolha de candidatos em todos os vinte e sete distritos.

Ignorando a possível intervenção da executiva nacional para as eleições de 2010, supomos que a seleção de candidatos no Brasil, em todos os partidos, é descentralizada territorialmente. Já a descentralização social pode ser observada na tabela 05 :

TABELA 5 - DESCENTRALIZAÇÃO SOCIAL NA SELEÇÃO DE CANDIDATOS NAS ELEIÇÕES DE 2010

\begin{tabular}{|l|c|c|c|c|c|}
\hline & \multicolumn{3}{|c|}{ Partido Político (\%) } & \\
\cline { 2 - 5 } & DEM & PMDB & PSDB & PT & Total \\
\hline Seleção por órgãos internos do partido & 96,7 & 100 & 96,7 & 96,7 & 97,5 \\
Indicação por associações ou instituições ligadas ao partido & 3,3 & 0,0 & 3,3 & 3,3 & 2,5 \\
$\mathrm{n}$ & 30 & 30 & 30 & 30 & 120 \\
Total & 100 & 100 & 100 & 100 & 100 \\
\hline
\end{tabular}

FONTE: o autor

Coef. Contingência $=p$ value $>0,795$.

26 Os autores não realizam a separação analítica entre descentralização territorial e organizativa. Apenas afirmam que essa nova perspectiva deve ser entendida a partir da percepção dos candidatos - como é aqui nossa proposta através do uso de survey-- e não deve ser confundida com graus de inclusividade, 
A mesma pergunta ${ }^{27}$ que norteou os dados da tabela anterior foi utilizada aqui para sabermos em que medida os candidatos contaram com a participação de organizações externas ao partido ao serem indicados nas listas eleitorais. A única diferença é que na tabela 04 apresentamos os dados desagregados por órgãos internos do partido e suprimimos o dado acerca das associações externas. Aqui, por outro lado, apresentamos os dados organizativos agregados numa só categoria e consideramos para fins de análise o papel das instituições ligadas ao partido.

Como mostra a tabela 05 , as associações ou instituições externas contam muito pouco no processo de indicação de candidatos para deputado federal. Nem mesmo em uma tabulação entre os partidos políticos encontramos alguma correlação estatisticamente significativa que nos permita crer que tais associações exerçam algum papel para a descentralização social da seleção de candidatos. Por outro lado, poderíamos pensar que a legislação que obriga os partidos políticos a contarem com $30 \%$ de candidatos de algum dos sexos resultaria numa descentralização social e no aumento da representatividade. Esta afirmação tem lastro empírico apenas em parte: é uma forma de descentralização do ponto de vista formal, uma exigência legal, conforme a lei 9.504/1997. Contudo, como mostra Bolognesi (2012), não havia nas eleições de 2010 qualquer punição para os partidos que não cumprissem esta determinação. Dentre os nossos entrevistados, a quantidade de mulheres ficou na casa de $14,2 \%$, não atingindo sequer a metade da exigência legal. Ou seja: não podemos atribuir a presença de mulheres nas listas às cotas. Somente quando se concretizar de modo claro o cumprimento da exigência legal, poderemos atribuir descentralização social para os partidos brasileiros. Para resumir: a partir destes dois indicadores não é possível falar em descentralização social nos partidos analisados. Vale notar, ainda, que o PMDB apresentou nulidade quanto à possibilidade de selecionar seus candidatos por associações externas.

Para examinar o último modo possível de descentralização sumarizamos os dados presentes nas tabelas 04 e 05 em um quadro que indica apenas o uso ou não de determinado selectorate. A existência de uma multiplicidade de selectorates indica não somente o método de seleção utilizado, como também a descentralização organizativa do mesmo.

QUADRO 1 - DESCENTRALIZAÇÃO ORGANIZATIVANA SELEÇÃO DE CANDIDATOS EM 2010 POR PARTIDO POLÍTICO

\begin{tabular}{|l|c|c|c|c|}
\hline & DEM & PSDB & PMDB & PT \\
\hline Filiados & Sim & Sim & Sim & Sim \\
Delegados do Partido & Sim & Sim & Não & Sim \\
Associações ou Instituições Ligadas ao Partido & Sim & Sim & Não & Sim \\
Líderes Partidários & Sim & Sim & Sim & Sim \\
Líder Único & Sim & Sim & Sim & Não \\
Total de selectorates mobilizados & 5 & 5 & 3 & 4 \\
\hline
\end{tabular}

FONTE: o autor.

Os dados do quadro acima apontam que DEM e PSDB contam com processos de descentralização organizativa mais intensos. Por outro lado, PT e PMDB mobilizaram menos suas esferas partidárias, com destaque para a maior centralização do PMDB, utilizando apenas três dos cinco possíveis selectorates. O gráfico abaixo sumariza a distribuição dos partidos quanto à descentralização social e organizacional, já que assumimos que a territorial seria fixa para todos eles. como coloca Lundell (2004). A inclusividade do selectorate é dada, como mostramos na seção anterior, pela participação, para usar os termos de Gallagher e Marsh (1988), de indivíduos e órgãos partidários no processo de seleção, sem importar-se se são mais de um selectorate ou vários combinados. Apesar de reconhecermos que, empiricamente, os métodos complexos são mais utilizados, a mobilização destes reflete também o grau de descentralização organizativa do partido, quando e somente se, utilizados mais de um selectorate.

27 “Tendo em vista sua experiência durante o processo de seleção de candidatos a deputado federal em seu partido, o senhor (a) diria que o processo é feito por:" 


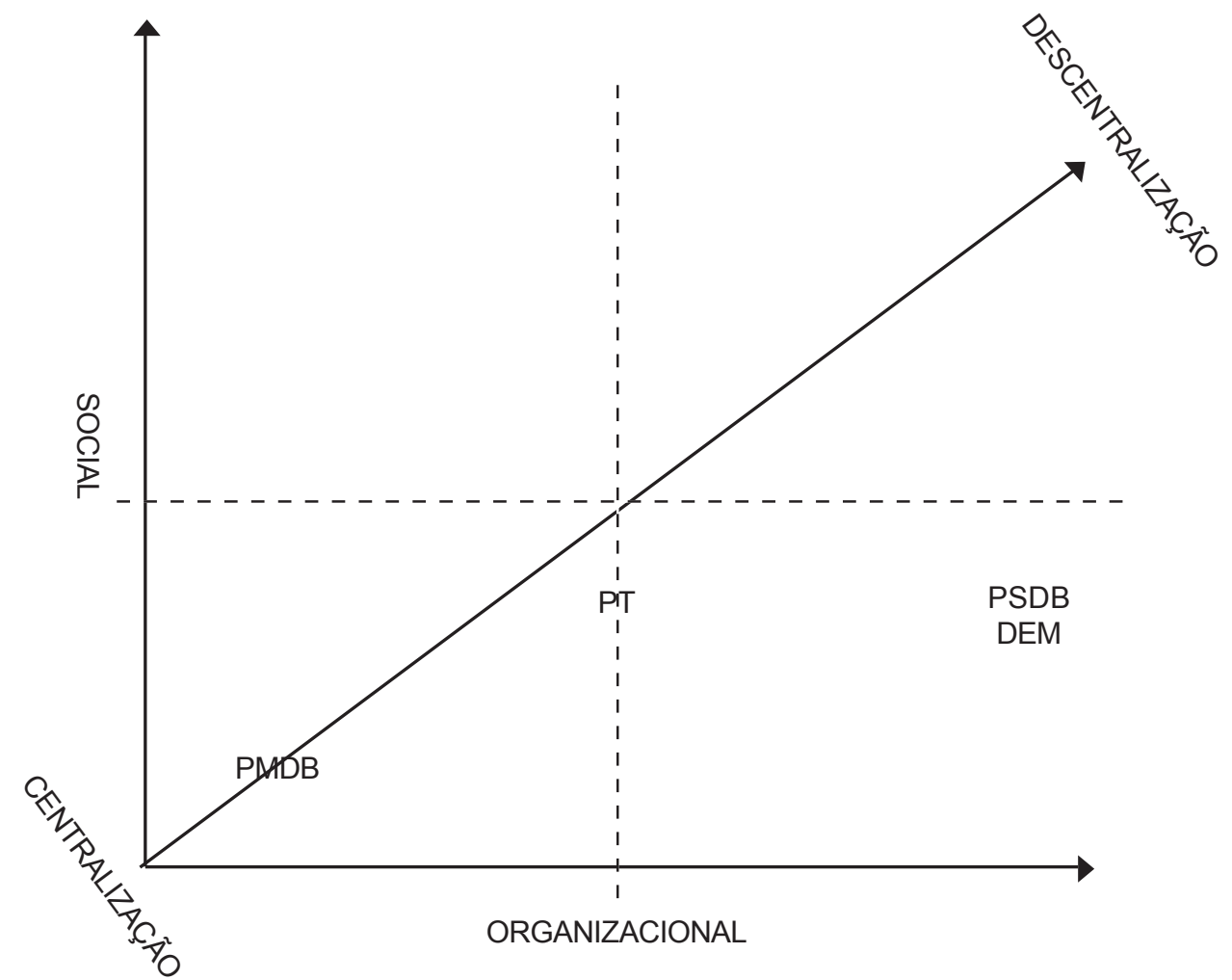

FONTE: O autor.

O PMDB encontra-se no quadrante esquerdo inferior, apresentando níveis mais centralizados para ambas as dimensões. O partido utilizou menos seus órgãos internos e sequer mobilizou, para a seleção de um único candidato, associações correlatas. Ao centro, temos o PT, que, assim como PSDB e DEM, teve o uso muito restrito de ligações externas para formar as listas de candidatos. Por fim, no alto do quadrante inferior direito, encontramos PSDB e DEM, que além da semelhança descentralizadora social mínima com os petistas, mobilizaram todos os níveis internos possíveis para escolherem seus candidatos.

Os dados são muito inconclusivos sobre todos os partidos. Não é possível estabelecer uma comparação que defina claramente as fronteiras da descentralização entre os mesmos. Neste sentido, podemos dizer que o a inclusividade do selectorate é, até agora, a dimensão que mais impacta as diferenças entre os partidos tomados como variáveis intervenientes. Nesse sentido, concordamos com Hazan e Rahat (2010), quando afirmam que os altos níveis de descentralização territorial, quando coincidem com a descentralização do sistema eleitoral, criam barreiras para que os partidos adotem mecanismos de descentralização social. Por outro lado, a mesma falta de unidade territorial nas eleições, onde cada partido goza de autonomia regional, cria uma multiplicidade de selectorates que estão associados aos distritos em que cada candidato é recrutado, aumentando níveis de descentralização organizacional.

Para o estabelecimento de lealdades, Siavelis e Morgenster (2009) afirmam que a descentralização do processo só reforça os determinantes da inclusividade do selectorate. Mesmo aceitando que grupos externos ou que a existência de vários selectorates possa mesclar a direção da lealdade, é em relação a quem seleciona o candidato, independente de onde isso ocorra, que a formação de laços será estabelecida. Desse modo, a descentralização do processo pode vir a reforçar laços com comunidades locais ou grupos de interesse que o candidato representa, por exemplo. Mas, tal descentralização está longe de romper a responsabilidade que o candidato possui com quem o levou até àquele posto.

A hipótese de Freidenberg (2003) sobre a descentralização dos processos é colocada em xeque na medida em que partidos que apresentaram níveis muito semelhantes de centralização, diferenciam-se substancialmente quanto à inclusividade do selectorate. Partindo desta comparação, concordamos com Billie 
(2001) ao afirmar que descentralização e inclusividade não revelam em conjunto de seleções de candidatos mais democráticas.

\section{COMO SÃO ESCOLHIDOS OS CANDIDATOS: VOTO OU INDICAÇÃO}

Candidatos escolhidos por sistemas de votação tendem a ser legitimados por este, ou seja: tendem a utilizar o voto a seu favor, na medida em que ele significa uma escolha realizada de forma supostamente mais democrática do que a dos sistemas de indicação. $\mathrm{Na}$ literatura há uma infinidade de discussões sobre a fórmula de votação utilizada nos partidos políticos (HAZAN \& RAHAT, 2010). Desde sistemas de lista fechada, voto transferível e sistemas proporcionais, como apontam, por exemplo, Luca, Jones e Tula (2002) ao analisarem a seleção de candidatos na Argentina. Porém, no caso do Brasil, não investigamos se nos sistemas de votação foi mobilizada alguma fórmula de voto baseada nas eleições. Apenas perguntamos aos candidatos se eles haviam sido indicados para a lista ou se passaram por escolhas através do voto. As respostas estão apresentadas na tabela 06 :

TABELA 6 - FORMA DE ESCOLHA POR PARTIDO NA SELEÇÃO DE CANDIDATOS EM 2010

\begin{tabular}{|c|c|c|c|c|c|}
\hline & \multicolumn{4}{|c|}{ Partido Político (\%) } & \multirow[b]{2}{*}{ Total } \\
\hline & DEM & PMDB & PSDB & PT & \\
\hline Indicação & 73,3 & 86,7 & 63,3 & 23,3 & 61,7 \\
\hline Std. Res. & 0,8 & 1,7 & 0,1 & $-2,7$ & \\
\hline Votação & 26,7 & 13,3 & 36,7 & 76,7 & 38,3 \\
\hline Std. Res. & -1 & $-2,2$ & $-0,1$ & 3,4 & \\
\hline$n$ & 30 & 30 & 30 & 30 & 120 \\
\hline Total & 100 & 100 & 100 & 100 & 100 \\
\hline
\end{tabular}

FONTE: o autor - Coef. Contingência $0,437=p$ value $<0,000$

A primeira evidência clara é que os partidos tendem, em geral, a indicar os candidatos para suas listas (independente de quem o faça), em vez de votar em seus futuros representantes. $61,7 \%$ das respostas revelam que a indicação é a forma de escolha predominante. Segundo Braga (2008), esse é um traço fundamental para rebater as conclusões que Mainwaring (1991) chega sobre o controle dos partidos sobre seus representantes. $\mathrm{O}$ uso de indicações seria, segundo a autora, um traço forte de que os partidos estão longe de não controlarem seus processos internos. Não seria correto, portanto, atribuir à combinação de lista aberta, fragilidade legislativa e multipartidarismo a suposta ausência de manejo que os partidos teriam sobre as zonas de incerteza.

O segundo ponto mais geral é que, para que um sistema seja classificado como sistema de votação ou sistema de indicação, é preciso que a forma de escolha seja única na determinação da lista de candidatos. É preciso ainda que tal forma legitime e justifique a candidatura (RAHAT, 2009). Novamente, nos casos concretos, temos sistemas mistos de formas de escolha. Nenhum dos quatro partidos apresentou apenas uma forma ou outra de seleção dos candidatos. Dito isso, algumas diferenças entre os partidos merecem ser destacadas.

Em primeiro lugar, é muito interessante o fato de que o PSDB não apresente, em todas as análises que conduzimos até agora, resíduos padronizados acima dos valores críticos para qualquer uma das variáveis. $\mathrm{O}$ partido tucano não apresenta universalismo procedimental em qualquer dimensão que analisamos neste trabalho. Em todos os dados apresentados, os peessedebistas acompanharam as médias dos outros três partidos enquanto não houve diferença entre eles e, quando houve, como no caso da inclusividade do selectorate, o partido se destacou por não apresentar proporções inesperadas em relação à distribuição dos seus pares. Ignorando os resíduos padronizados, podemos dizer que o PSDB, dentre os partidos que utilizam majoritariamente sistema de indicação, é o mais democrático, contando com $36,7 \%$ das respostas de seus candidatos associadas à votação como forma de sua escolha.

Seguindo para o DEM (que também não apresentou resíduos padronizados significativos para esta dimensão), há também o predomínio de indicações em vez de votações para a escolha dos candidatos. Mais acentuado do que o PSDB, porém, a percepção que os candidatos demistas apresentam coloca o partido em posição muito próxima à dos tucanos no que se refere a forma de escolha como critério para avaliação da democracia interna. $73,3 \%$ dos candidatos responderam que foram indicados para as listas de 
partido - acima dos tucanos e ainda abaixo do PMDB, que apresentou índices de votação muito baixos.

O PMDB poderia ser classificado, numa perspectiva comparativa entre esses quatro, como o menos democrático quanto à forma de escolha. $\mathrm{O}$ partido não difere significativamente dos demais quanto ao uso de indicação. Porém, os resíduos negativos na casa de 2,2 para mobilização de votos, mostram que, em relação aos demais, o partido se diferencia muito além do esperado e no sentido oposto, ou seja: com menor proporção de candidatos que foram selecionados por votos do que a diferença entre o esperado e o observado para os outros partidos.

Já o PT foi o único partido que apresentou resíduos positivos $(3,4)$ acima do valor crítico para a percepção de que seus candidatos chegaram até a lista final de candidatos pelo voto. $\mathrm{E}$ ao mesmo tempo, apresentou resíduos significativamente negativos $(-2,7)$ para as indicações de candidaturas. A oposição entre tais valores não é óbvia, como vimos no caso do PMDB. Os resíduos nos ajudam a enxergar aquilo que pode estar mascarado pela distribuição das freqüências relativas entre os partidos. $\mathrm{O}$ fato de termos uma larga diferença entre votação e indicação no caso petista poderia não refletir numa diferença em relação aos seus pares nas eleições de 2010, por exemplo. Portanto, podemos afirmar com segurança que o PT foi o partido que apresentou melhores indicadores de democracia interna.

Sistemas nos quais predominam indicações tendem a garantir maior coesão das escolhas do partido como um todo. Esse caso só é violado quando prevalecem indicações de um líder único do partido, o que não ocorreu nas eleições apresentadas neste artigo. Mudanças no sentido de sistemas de voto são encaradas como processos de democratização da seleção de candidatos e um bom indicador de democracia interna dos partidos políticos (RAHAT, 2009). Porém, isso não garante que encontremos maior representatividade quando os candidatos são escolhidos dessa forma. Hazan e Rahat (2010) afirmam que processos em que líderes controlam a seleção tendem a garantir oportunidades melhores para a inserção de minorias. Segundo Rahat, Hazan e Katz (2008), isso ocorre em grande medida, pois o voto secreto, tido como norma democrática, tende a desconsiderar a preservação de minorias, revertendo-se numa ditadura da maioria.

\section{CONCLUSÃO: AS CONSEQUÊNCIAS DO PROCESSO DE SELEÇÃO PARA A DEMOCRACIA INTERNA NOS PARTIDOS POLÍTICOS.}

Para auferirmos democracia interna, levaremos em conta as quatro dimensões analisadas: requisitos para candidatura, selectorate, descentralização e forma de escolha. O quadro abaixo sumariza, com scores para cada dimensão, os dados encontrados para cada partido. Apenas para descentralização adotamos o critério de 0 para descentralizado e 1 para centralizado. Para as dimensões de forma de escolha e requisitos para candidatura, atribuímos 0 quando a dimensão era não inclusiva e 1 para dimensões inclusivas. Para o selectorate, utilizamos uma escala mais detalhada, que fosse capaz de captar as diferenças entre os partidos. Assim, atribuímos 0 para seleção majoritariamente conduzida por lideranças e/ou líder único e com baixa ou nenhuma ausência de participação de instâncias intermediárias ou de base; 1 para seleções majoritariamente dominadas por líderes, mas com baixa presença de líder único e com alguma presença de líderes intermediários; e 2 para seleções com ausência do pólo mais exclusivo e majoritariamente dominadas por seleção realizada por instâncias intermediárias e de base.

QUADRO 2 - SUMARIZAÇÃO DE SCORES PARA DEMOCRACIA INTERNA NOS PARTIDOS POLÍTICOS

\begin{tabular}{|l|c|c|c|c|c|}
\hline & $\begin{array}{c}\text { Requisitos para } \\
\text { Candidatura }\end{array}$ & Selectorate & Descentralização & $\begin{array}{c}\text { Forma de } \\
\text { Nominação }\end{array}$ & Score Total \\
\hline DEM & 1 & 0 & 1 & 0 & 2 \\
PMDB & 1 & 0 & 1 & 0 & 2 \\
PSDB & 1 & 1 & 1 & 0 & 3 \\
PT & 0 & 2 & 1 & 1 & 4 \\
\hline
\end{tabular}

FONTE: o autor.

Como podemos ver no quadro acima, o PT é o partido que contou com maior score dentre os analisados. Isso se dá, em grande medida, pela diferença significativa que o partido apresenta em relação aos selectorates dos seus pares. A atribuição destes valores tem, é claro, um elemento circunstancial. $\mathrm{O}$ fato de o selectorate do PT receber pontuação dobrada em relação ao PSDB, por exemplo, não deve ser entendido como um peso dobrado ao contar com procedimentos mais democráticos. Os valores atribuídos referem-se 
no predomínio ou não de certa característica, como na forma de nominação, ou uma distribuição mais equânime das proporções apresentadas pelos partidos. Por outro lado, todos os partidos foram classificados como tendo seleções descentralizadas. Dessa forma, o PT é o partido com melhores níveis gerais de democracia, seguido pelo PSDB e partilhando níveis iguais aos do PMDB e do DEM.

Como dissemos na introdução deste artigo, apresentamos abaixo as conseqüências do processo de seleção essencialmente para o critério de representação de minorias. Os dados que temos à disposição nos permitem falar acerca da participação das mulheres nas listas eleitorais de cada partido. A hipótese de trabalho era que partidos com processos de seleção de candidatos mais democráticos apresentariam também conseqüências mais democráticas, ou seja, maiores indicadores de representatividade. Nos estudos de recrutamento político, instituições são consideradas mais representativas se conseguem refletir minimamente a composição social de seus membros. Já na literatura sobre partidos e sistemas eleitorais, a representação está ligada à capacidade que o sistema eleitoral tem de converter votos em cadeiras legislativas. Num ponto ideal possível, os partidos deveriam dar oportunidades para que mulheres disputassem posições que se revertessem em cadeiras. Assim, as duas condições (social e institucional) estariam cumpridas.

Para medir a representatividade, utilizamos o caso das mulheres num indicador adaptado de Hazan e Rahat (2010). O indicador criado pelos autores, chamado de Index of Representation (IR), foi inicialmente forjado para sistemas de seleção de candidatos que utilizam listas fechadas. Nestes tipos de sistemas, os líderes dos partidos conseguem determinar quais são os chamados safe-seats - as posições seguras dentro da lista para que o candidato seja selecionado. Por exemplo, numa lista na qual se espera selecionar cinco candidatos, as cinco primeiras posições são classificadas como safe-seats. Porém, para o caso brasileiro, no qual não há formato de seleção de candidatos formalmente institucionalizado, podemos imaginar que o número de safe-seats de cada partido é dado pela quantidade de candidatos à reeleição. Os incumbents, como dissemos antes, desfrutam de larga margem de vantagem para o pleito eleitoral, o que permite que os classifiquemos como detentores de posições seguras nas listas abertas.

O indicador original dava a proporção de mulheres em safe-seats pelo total de safe-seats. No nosso caso, utilizaremos a proporção do total de mulheres candidatas à reeleição, dividido pelo total de candidatos à reeleição. Quanto maior o indicador, melhor o nível de representação dentro do partido em relação à disposição da conquista de votos através dos incumbents.

$$
\text { Indicador de Representatividade }(I R)=\frac{I W}{T I} * 100
$$

$I W$ representa o total de mulheres candidatas à reeleição

TI representa o total de candidatos à reeleição de ambos os sexos.

Outra forma de avaliar a inserção de mulheres nos partidos político é medir a taxa de desafio destas em relação à quantidade de safe-seats disponíveis. Ou seja, saber quantas mulheres desafiantes, portanto, que não disputam a reeleição e se apresentam em relação à quantidade de safe-seats disponíveis. Quanto mais alto o indicador, mais competição temos em relação às mulheres novatas, quanto menor o indicador, mais provável é que essas mulheres tenham oportunidade de se fazerem representadas renovando o partido.

Da mesma forma que o anterior, adaptamos o indicador de desafiantes de Rahat, Hazan e Katz (2008) para listas abertas.

$$
\text { Índice de Renovação Relativa }(I R R)=\frac{A W}{T I M}
$$

Onde $A W$ representa a quantidade de mulheres que não concorrem pela reeleição

TIM o total de candidatos homens que disputam a reeleição.

Os dados apresentados na tabela 07 abaixo foram calculados a partir de todo o universo de candidatos nas eleições de 2010.

TABELA 7 - REPRESENTATIVIDADE DE MULHERES

\begin{tabular}{|lcc|}
\hline Partido & IR & IRR \\
\hline DEM & 7,4 & 0,76 \\
PMDB & 8,77 & 1 \\
PSDB & 5,12 & 1,45 \\
PT & 8,62 & 1,24 \\
\hline
\end{tabular}

FONTE: TSE (2012)

Os dados da tabela 07 apontam três conclusões: em primeiro lugar, não é possível dizer que partidos mais democráticos internamente possuem melhores indicadores de representatividade (IR); PMDB e PT apresentaram ambos os valores próximos de nove, enquanto que um apresentou score democrático muito mais baixo do que outro. O mesmo vale para PSBD e 
DEM, não parecendo haver, pelo menos aqui, sustentação empírica para associar representatividade com democracia interna.

Em segundo lugar, o fato de termos representação não significa que os grupos minoritários encontrarão espaço dentro dos partidos. Partidos com alto indicador de representatividade, como o $\mathrm{PT}$, oferecem, ao mesmo tempo, muita competição. Por outro lado, o lugar onde as chances são menores para as mulheres é o PSDB, com baixos níveis de representação e altos de renovação relativa. O melhor desempenho na comparação dos dois indicadores fica com o PMDB, que apresenta a mais alta taxa de representatividade e a segunda menor taxa de renovação relativa.

Muito provavelmente, não são os nossos indicadores que não fazem sentido. É que talvez não seja suficiente utilizar a seleção de candidatos e as composições das listas para entender de que forma os partidos manejam a representação política. Desse ponto de vista, Norris e Lovenduski (1997), argumentam que somente com o estudo sobre a quantidade de mulheres que não chegam a se tornar candidatas é que podemos compreender o motivo pelo qual os indicadores de representatividade são relativamente baixos e os anteparos à renovação relativamente $\operatorname{altos}^{28}$.

Se, por um lado, não conseguimos com nossos dados comprovar a hipótese de trabalho que pretendíamos, por outro, conseguimos mostrar que a seleção de candidatos pode ser um bom indicador para mensurar democracia interna nos partidos políticos. Sustentamos que é preciso uma investigação mais ampla, com maior quantidade de casos e maior quantidade de partidos para que possamos chegar a conclusões mais satisfatórias. Contudo, o uso da metodologia de survey nos pareceu muito adequada para compreender de que modo operam os partidos políticos ao formarem suas listas de candidatos.

Uma limitação importante é que não foi verificada aqui a forma com que os líderes e membros do selectorate do partido operam a seleção de candidatos. Pesquisas futuras poderiam debruçar esforços no sentido de compreender numa perspectiva dialógica a seleção de candidatos em si, a partir de selecionadores e selecionadores e as conseqüências deste processo para a qualidade democrática.

Bruno Bolognesi (brunobolognesi@gmail.com) é doutor em Ciência Política pela Universidade Federal de São Carlos e (UFSCar) e professor do curso de Ciência Política e Sociologia da Universidade Federal da Integração Latino Americana (UNILA).

\section{REFERÊNCIAS BIBLIOGRÁFICAS}

ÁLVARES, M. L. M. 2008. Recrutamento Político \& Seleção de Candidaturas: acesso às listas e o papel das lideranças no "jardim secreto". Paper apresentado no $6^{\circ}$. Encontro da $A B C P$. Campinas.

AMARAL, O. 2011. Ainda Conectado: o PT e seus vínculos com a sociedade. Opinião Pública. vol. 17, n. 1, p. 01-44.

AMES, B. \& POWER, T. J. 2007. Parties and Governability in Brazil. In: Webb, P. e White, S. Party Politics in New Democracies. Oxford: Oxford University Press.

ARAÚJO, C \&BORGES, D. 2012. O "gênero" e os "não-elegíveis": uma análise das candidaturas para a Câmara Federal em 2010. In: Alves, J. E. D.; Jardim, C. R.; Jordão, F. (orgs.). Mulheres nas eleições 2010. São Paulo: ABCP/Secretaria de Políticas para as Mulheres.

BARNEA, S \& RAHAT, G. 2007. Reforming Candidate Selection Methods: a three-level approach. Party Politics. vol. 13, n. 3, p. 375-394.

BOLOGNESI, B. 2012. A cota eleitoral de gênero: política pública ou engenharia partidária? Paraná eleitoral: revista de direito eleitoral e ciência politica. vol. 1, n. 2, p. 113-129.

BILLIE, L. 2001. Democratizing a Democratic Procedure: myth or reality?: candidate selection in Western European Parties, 1960-1990. Party Politics. vol. 7, n. 3, p. 363-380.

BRAGA, M. S. S. 2008. Organizações partidárias e seleção de candidatos no estado de São Paulo. Opinião Pública, vol. 14, n. 2, p. 454-485.

2009. Reclutamiento partidista y representación: proceso de selección de candidatos en la Cámara de Diputados Brasileña. In: Freidenberg, F. e Saez, M. A. Selección de Candidatos, Política Partidista

\footnotetext{
28 Um bom começo para isso seja talvez observar que os partidos tem baixíssima capacidade de atrair seus membros para candidaturas. A relação candidatos por filiados nos partidos foi de: DEM 0,016; PMDB 0,014; PSDB 0,019; PT 0,022 (Fonte: TSE, 2012), o que evidencia que é preciso buscar fora dos partidos explicações para a não inserção de minorias nas listas eleitorais.
} 
y Rendimiento Democrático. D.F. México: Tribunal Electoral del Distrito Federal.

\& BOLOGNESI, B. 2013. Dimensões do Processo de Seleção da Classe Política Brasileira: autopercepções dos candidatos à Câmara dos Deputados nas eleições de 2010. In: MARENCO DOS SANTOS, A. (org.). Os Eleitos. Representação e carreiras políticas em democracias. Porto Alegre: Editora UFRGS.

VEIGA, L. F.; MIRÍADE, A. 2009. Recrutamento e perfil dos candidatos e dos eleitos à Câmara dos Deputados nas eleições de 2006. Revista Brasileira de Ciências Sociais. vol. 24, n. 70. p. 123-142.

\& BOURDOUKAN, A. 2007. Partidos Políticos no Brasil: organização partidária, competição eleitoral e financiamento público. Perspectivas, vol. 35, p. 117-148.

CROSS, W. 2008. Democratic Norms and Party Candidate Selection: taking contextual factors into account. Party Politics. vol. 14, n. 5, p. 596-619.

CZUDNOWSKI, M. 1975. Political Recruitment. In: Greenstein, F. e Polsby, N. Handbook of Political Science. Micropolitical Theory. Vol. 2. Reading: Addison-Wesley Publishing Company.

DESPOSATO, S. W. 2006. How Informal Electoral Institutions Shape the Brazilian Legislative Arena. In: Helmek, G. e Levitsky, S (eds.). Informal Institutions \& Democracy. Lessons from latin america. Baltimore: The Johns Hopkins University Press.

FREIDENBERG, F. 2002. Incentivos Electorales y Selección de Candidatos en Organizaciones Neopopulistas: el Partido Roldosista Ecuatoriano (1984-2000). Paper apresentado no V Congreso de la Asociación Española de Ciencia Política y de la Administración. Tenerife.

2003. Selección de Candidatos y Democracia Interna en los Partidos de la América Latina. Biblioteca de La Reforma Política. n.1.

. 2006. La democratización de los partidos políticos en la América Latina: entre la ilusión y el desencanto. In: Thompson, J. e Sánchez, F. Fortalecimiento de los partidos politicos en América Latina: institucionalización, democratización y transparencia. San José de Costa Rica: IIDH.

2009. ¿Qué es la democracia interna? Una propuesta de redefinición conceptual. La democracia en su contexto. Estudios en homenaje a Dieter Nohlen en su septuagésimo aniversario. In: Reynoso Núñez, José e Sánchez de la Barquera y Arroyo,
Herminio. México, D.F.: Instituto Investigaciones Jurídicas, p. 277-295.

GALLAGHER, M. 1980. Candidate Selection in Ireland: the impact of localism and the electoral system. British Journal of Political Science. Vol. 10, n. 4, p. 489-503.

\& MARSH, M. 1988. Candidate Selection in Comparative Perspective. The secret garden of politics. London: Sage Publications.

HAZAN, R. 2002. Candidate Selection. In: LEDUC, L.; NIEMI, R.; NORRIS, P. (eds.). Comparing Democracies. vol. 2. Thousand Oaks: Sage.

\& RAHAT, G. 2007. The influence of candidate selection methods on legislatures and legislators: theoretical propositions, methodological suggestions, and empirical evidences. The Journal of Legislative Studies. vol. 12, n. 3-4, p. 366-385.

2010. Democracy Within Parties. Candidate selection methods and their political consequences. Oxford: Oxford University Press.

HAZAN, R \& VOERMAN, G. 2006. Electoral Systems and Candidate Selection. Acta Politica. n. 46, p. 146-162.

HOPKIN, J. 2001. Bringing the Members Back In?: democratizing candidate selection in Britain and Spain. Party Politics. vol. 07, n. 3, p. 343-361.

KATZ, R. 2001. The problem of candidate selection and models of party democracy. Party Politics. vol. 07, n. 3, p. 277-296.

KOOP, R. \& BITTNER, A. 2011. Parachuted into Parliament: candidate nomination, appointed candidates, and legislative roles in Canada. Journal of Elections, Public Opnion and Parties. vol. 21, n. 4, p. 431-452.

LEVITSKY, S. 2009. Institutionalization: unpacking the concept and explaning party change. In: Coollier, D. e Gerring, J. Concepts and Method in Social Science. The tradition of Giovanni Sartori. Oxford: Routledge.

LUCA, M. D.; JONES, M. P; TULA, M. I. 2002. Back Rooms or Ballot Boxes? Candidate nomination in Argentina. Comparative Political Sutdies. vol. 35, n. 4, p. 413-436.

LUNDELL, K. 2004. Determinants of Candidate Selection. The degree of centralization in comparative perspective. Party Politics. vol. 10, n. 1, p. $25-47$.

MAINWARING, S. 1991. Políticos, Partidos e Sistemas Eleitorais. Novos Estudos. n. 29. 
\& SCULLY, T. R. 1997. La Institucionalización de los Sistemas de Partido en América Latina. América Latina Hoy. vol. 16, p. 91-108.

MARENCO DOS SANTOS, A. \& SERNA, M. 2007. Por que carreiras políticas na esquerda e na direita não são iguais? Recrutamento legislativo em Brasil, Chile e Uruguay. Revista Brasileira de Ciências Sociais. vol. 22, n. 64, p. 93-113.

NORRIS, P. \& LOVENDUSKI, J. 1997. United Kingdom. In: Norris, P. (ed.). Passages to Power. Legislative recruitment in advanced democracies. Cambridge: Cambridge University Press. p. 158186.

OBLER, J. 1974. Intraparty Democracy and the Selection of Parliamentary Candidates: the Belgian Case. British Journal of Political Science. vol. 04, n. 2. p. 163-185.

PANEBIANCO, A. 2005. Modelos de Partido. Organização e poder nos partidos políticos. São Paulo: Martins Fontes.

PATERSON, P. 1967. The Selectorate. The Case for Primary Election on Britain. London: MacGibbon \& Kee.

PENNINGS, P \& HAZAN, R. 2001. Democratizing Candidate Selection. Causes and Consequences. Party Politics. vol. 7, n. 3, p. 267-275.

PERISSINOTTO, R. M. \& BOLOGNESI, B. 2009. O Recrutamento Político no PT e PFL Paranaenses nas Eleições de 2006: sugestões de pesquisa. $M e-$ diações. vol. 14, n. 1, p. 143-169.

2010. Electoral Success and Political Institutionalization in the Federal Deputy Elections in Brazil (1998, 2002 and 2006). Brazilian Political Science Review. vol. 4, n. 1. p. 10-32.

PREWITT, K. 1970. The Recruitment of Political Leaders: A Study of Citizen-Politicians. Indianapolis/New York: The Bobbs-Merril Company.

RAHAT, G. 2009. Which Candidate Selection Method is the Most Democratic?. Government and Opposition. vol. 44; n. 1. p. 68-90.
\& HAZAN, R. 2001. Candidate selection methods: an analitycal framework. Party Politics. vol. 07, n. 3, p. 297-322.

\& KATZ, R S. 2008. Democracy and Political Parties. On the uneasy relationships between participation, competition and representation. Party Politics. vol. 14, n. 6, p. 663-683.

RANNEY,A. 1965. Pathways to Parliament. Candidate selection in Britain. Madison and Milwaukee: The University of Wisconsin Press.

ROSENBERG, M. 1976. A lógica da Análise do Levantamento de Dados. São Paulo: Editora Cultrix/ Edusp.

RUSH, M. 1969. The Selection of Parliamentary Candidates. London: Thomas Nelson and Sons.

SAMUELS, D. 2008. Political Ambition, Candidate Recruitment, and Legislative Politics in Brazil. In: Siavelis, P. e Morgenstern, S. Pathways to Power: political recruitment and candidate selection in Latin America. University Park: The Pennsylvania State Univeristy.

SCHATTSCHNEIDER, E. 1942. Party Government. New York: Holt, Rinehart and Winston.

SIAVELIS, P \& MORGENSTERN, S. 2009. Reclutamiento y selección de candidatos en América Latina: un marco para el análisis. In: FREIDENBERG, F. e SAEZ, M. A. Selección de Candidatos, Política Partidista y Rendimiento Democrático. D.F. México: Tribunal Electoral del Distrito Federal.

SURI, K. C. 2007. Political Parties in South Asia: the challange of change. Estocolmo: International Institute for Democracy and Electral Assitance.

VEIGA, L. 2007. Os partidos brasileiros na perspectiva dos eleitores: mudanças e continuidades na identificação partidária e na avaliação das principais legendas após 2002. Opinião Pública, vol. 13, n. 2, p. 340-365.

WARE, A. 1996. Partidos politicos y sistemas de partido. Madrid: Ediciones Istmo.

\section{OUTRAS FONTES}

TSE. 2012. Sítio do Tribunal Superior Eleitoral. Disponível em: http://www.tse.jus.br. Acesso em: 11.jun.2013. 
THE CANDIDATE SELECTION IN DEM, PMDB, PSDB AND PT IN THE BRAZILIAN'S 2010 FEDERAL LEGISLATIVE ELECTIONS: CANDIDATES PERCEPTION FROM PARTY LIST BUILDING

\section{Bruno Bolognesi}

Candidate selection in Brazil was poorly treated in regarding the perception candidates have of the entire process. Thereby, the purpose of this article is to analyse decision making process of choosing candidates in the four greatests brazilian parties, DEM, PMDB, PSDB and PT. From this analisys, stablish empirical criteria for the internal democracy measure within political parties. In order to, we applied a survey to 120 federal deputies candidates in the 2010 election. The framework for analisys was the proposed by Freidenberg (2003) for the definition and measure of internal democracy and Hazan e Rahat (2010) for the candidate selection process. The hypothesis stands for more inclusive selections and done by vote, produces more democratic parties. The results points out that political parties with middle strata's organizational participation, as delegates, and mobilize the vote for the decision making process, not always presents better representative index. In the other hand, political parties selects thier candidates em very different way, independent from 
institutional constraint. Thesse differences ocurred essentialy regards the inclusiviness and the nomination shape. This points out that the electoral system isn't the exclusive determinant of the party behavior.

KEYWORDS: candidate selection; political parties; internal democracy; 2010 Brazil's elections. 